\title{
Hydrogen Transfer Reactions of Carbonyls, Alkynes, and Alkenes with Noble Metals in the Presence of Alcohols/Ethers and Amines as Hydrogen Donors
}

\author{
Eszter Baráth \\ Department of Chemistry and Catalysis Research Center, Technische Universität München, Lichtenbergstr. 4, \\ D-85748 Garching, Germany; eszter.barath@tum.de; Tel.: +49-89-289-13545
}

Received: 28 October 2018; Accepted: 17 December 2018; Published: 19 December 2018

\begin{abstract}
Hydrogen transfer reactions have exceptional importance, due to their applicability in numerous synthetic pathways, with academic as well as industrial relevance. The most important transformations are, e.g., reduction, ring-closing, stereoselective reactions, and the synthesis of heterocycles. The present review provides insights into the hydrogen transfer reactions in the condensed phase in the presence of noble metals $(\mathrm{Rh}, \mathrm{Ru}, \mathrm{Pd})$ as catalysts. Since the H-donor molecules (such as alcohols/ethers and amines $\left(1^{\circ}, 2^{\circ}, 3^{\circ}\right)$ ) and the acceptor molecules (alkenes $(\mathrm{C}=\mathrm{C})$, alkynes $(\mathrm{C} \equiv \mathrm{C})$, and carbonyl $(\mathrm{C}=\mathrm{O})$ compounds) play a crucial role from mechanistic viewpoints, the present summary points out the key mechanistic differences with the interpretation of current contributions and the corresponding historical achievements as well.
\end{abstract}

Keywords: hydrogen transfer; asymmetric hydrogen transfer; hydride; noble metals; alcohols; amines

\section{Introduction}

Transfer hydrogenation (TH) is a reaction in which $\mathrm{H}$ is transferred to an acceptor molecule from another molecular species (other than molecular hydrogen) acting as a donor. It is a movement of a hydride ion and proton (or two protons and two electrons), where the actual mechanism of the $\mathrm{H}$-transfer depends on the catalyst, the substrate, and the reaction conditions [1,2].

The first transfer hydrogenation (in 1925) was discovered by Meerwein and Schmidt using alcohols as the $\mathrm{H}$-source in the presence of aluminium alkoxide as a homogeneously acting catalyst for the reduction of carbonyl compounds [3] (further opportunities towards additional applicability of the reaction were studied by Verley [4], Ponndorf [5], and Lund [6]). Later on, reversing of the reaction was applied in oxidation reactions and was studied by Oppenauer [7]. In recent times, $\mathrm{Ln}^{\mathrm{III}}$ - [8,9] and $\mathrm{Al}^{\mathrm{III}}$-alkoxides [10], as well as $\mathrm{Al}^{\mathrm{III}}$ dinuclear complexes [11,12] were used as catalysts in Meerwein-Ponndorf-Verley and Oppenauer (MPVO) reactions, showing high catalytic activity $[13,14]$. In the 1960s, Mitchell published the saturation reaction of cyclohexanone to cyclohexanol in the presence of chloroiridic acid $\left(\mathrm{H}_{2} \mathrm{IrCl}_{6}\right)$ with trimethyl phosphite in aqueous 2-propanol (IPA), with water acting as the $\mathrm{H}$-source [15].

Transition metal catalysts such as the Wilkinson complex $\left(\mathrm{Rh}\left(\mathrm{PPh}_{3}\right)_{3} \mathrm{Cl}\right)$ showed remarkable activity in hydrogen transfer reactions as well [16]; however, the system is best known for hydrogenation reactions with molecular hydrogen. Not only rhodium, but also iridium and ruthenium complexes have been studied for reductive transfer hydrogenation reactions. In comparison, the TOF (turnover frequency) values obtained for transition metal-based catalysts surpass those obtained for the MPVO catalysts. The usage of additives such as bases further increased the catalytic activity [17-19]. Base molecules deprotonate the substrate and have the effect of increasing the catalytic activity, 
because the complexation of the substrate with the metal ion (in the intermediate complex formed) is promoted [17-19].

The chemical nature of transfer hydrogenation reactions has been studied extensively from many points of view. The most representative reaction was observed with alcohols. However, the scope of the reaction can be extended to other molecules that may be the donor or the acceptor molecule. Amines, carbonyl compounds, imines, and carboxylic acids (such as formic acid, it is usually mixed with $\mathrm{NEt}_{3}$ (TEAF) [20,21], in order to make the hydrogen transferring irreversible [22-26]), can serve as the H-source, allowing carbon-carbon double and triple bonds to be reduced in this way.

Hydrogen transfer reactions have many advantages over other hydrogenation methods. As described above, alcohols are frequently used as H-donors. Despite the fact that alcohols are easily available, have reactivity at mild conditions, and high selectivity, they provide the possibility of the usage of the $\mathrm{H}$-donor molecule as the reaction media as well (no mass transfer limitations). Hydrogen transfer reactions are reversible reactions and can be used in racemization reactions in combination with kinetic resolutions of racemic molecules [27]. Selective transfer of a hydrogen is also possible in the presence of chiral ligands (asymmetric transfer hydrogenation, ATH) [21,28].

Based on the large spectrum of hydrogen transfer reactions, the present review will focus on the results obtained with noble metals ( $\mathrm{Rh}, \mathrm{Ru}, \mathrm{Pd}$ ), in combination with alcohols/ethers and amines as H-donor species, whereas carbonyl compounds, alkenes, and alkynes act as acceptor molecules. Reactions in which the donor molecule is implemented in the structure of the final product are not a part of this review. Summarizing further contributions to the field, an excellent review has been recently published by Astruc et al., about hydrogen transfer reactions that are catalyzed by Fe-, Ru-, Os-, $\mathrm{Co}-$, $\mathrm{Rh}-, \mathrm{Ir}-, \mathrm{Ni}-, \mathrm{Pd}-$, and $\mathrm{Au}-$ related systems, as well as organocatalysts, bi- and multimetallic catalysts, and heterogeneous transition metal catalysis [29]. The nature of hydrogen transfer has been overviewed by Hynes/Klinman/Limbach/Schowen from many different angles including chemical and spectroscopic viewpoints [2]; moreover, the key aspects of enzyme-related hydrogen transfer reactions has been described as well [30].

\section{Hydrogen Transfer Reactions, Reaction Mechanisms}

The mechanism of a hydrogen transfer reaction depends strongly on the particular metal and the starting material. Two main pathways can be differentiated, the direct and the indirect mechanisms. Within the direct transfer pathway, $\mathrm{H}$ is transferred directly (Scheme 1, pathway $\mathbf{A}$ ) from the donor to the acceptor molecule; in the case of an indirect mechanism (Scheme 1, pathway B) a metal hydride intermediate forms. Strong Lewis acids such as $\mathrm{Al}^{\mathrm{III}}$ and $\mathrm{Ln}^{\mathrm{III}}$ ions are the most relevant representatives of the direct reaction type. Weak Lewis acids like $\mathrm{Rh}, \mathrm{Ru}$, and $\mathrm{Ir}$, with high affinities for hydrides, are the catalytically most active systems [1].

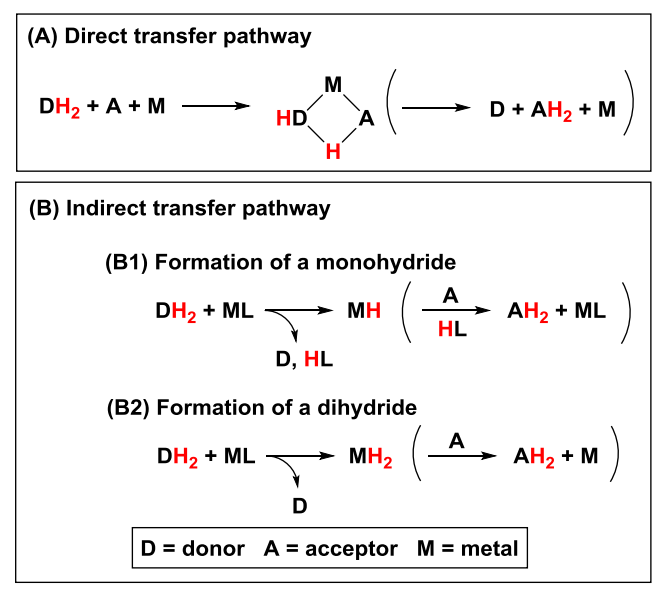

Scheme 1. Transfer hydrogenation mechanisms, direct (A) and indirect (B) pathways. 
Strong Lewis acid metal ions are able to coordinate the donor and the acceptor molecule, activate them via polarization, and promote an intramolecular H-shift (A pathway). Depending on the particular catalyst, the intermediate metal hydride complex formed can transfer one (Scheme 1, pathway B1) or two hydrides (Scheme 1, pathway B2) to the acceptor molecule (Scheme 1) [1].

Hydrogen transfer reactions are equilibrium reactions. The dominance of the reduction/oxidation pathways are highly dependent on the concentration of the donor and acceptor molecules and the thermodynamic stability of the species involved in the redox equilibrium [1].

\subsection{Hydrogen Transfer}

\subsubsection{Donor Molecules: Alcohols/Ethers and Amines}

An appropriately selected donor molecule (Figure 1) provides the hydrogen of a transfer reaction. The most beneficial choice, if the donor molecule is able to coordinate to the catalytic center, allows the abstraction of hydrogen (low oxidation potential) with control by the catalyst under relatively mild conditions when the donor is not strongly bound to the catalytic center after the donation is achieved [1].

The choice of a donor molecule depends mainly on the following parameters: (a) the type of reaction (transition metal-catalyzed, MPVO catalysts, etc.); (b) the chemical nature of the targeted functional group that is to be converted; (c) the solubility in the reaction medium (ability to act as a solvent of the corresponding reaction); (d) the influence on the equilibrium of the reaction; (e) no formation of toxic side products; (f) allows mild reaction conditions; (g) and the rate of the exchange between the metal-linked and the bulk form of the donor molecule [1].

Alcohols represent the major group as source of hydrogen in transfer reactions. Primary and secondary alcohols can be used, however, based on the sigma inductive electronic effect, and secondary alcohols are better donor molecules then the primary counterparts (ethanol). It was observed that aldehydes formed from primary alcohols (as donors) may act as catalyst poisons. They can decompose during the reaction and form $\mathrm{CO}$ molecules (formed by decarbonylation, a side reaction) that are able to hinder the catalytic activity of the metals used [31,32]. One of the most frequently used donor species is 2-propanol. It is an inexpensive, non-toxic, commercially available compound. This molecule has the advantage of acting as a solvent of a transfer reaction as well; moreover, the huge excess of the donor species promotes the shift of the redox equilibrium in the direction of the desired product. The consequence of the hydrogen transfer is the formation of acetone, which can be easily removed from the reaction mixture, representing a further benefit of the system.

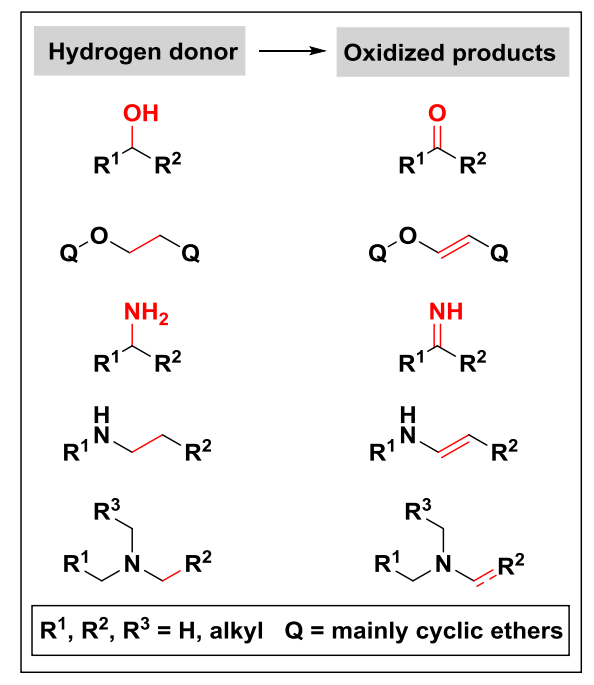

Figure 1. Selected hydrogen donor molecules and their oxidized derivatives. 
Heterocyclic molecules such as cyclic ethers, 1,4-dioxane, and 2,3-dihydrofuran are commonly used donor molecules in saturation reactions of alkenes and alkynes, in combination with transition metals $[33,34]$ as catalysts. They are able to donate a pair of hydrogen atoms, while they are excellent solvents as well $[35,36]$.

Nitrogen-containing materials, such as primary, secondary, and tertiary amines are also frequently used hydrogen sources in combination with transition metals. Piperidine, pyrrolidine, and indoline have been used for the reduction of aldehydes, alkenes, and alkynes [37,38].

\subsubsection{Acceptor Molecules: Carbonyls, Alkenes, and Alkynes}

Transfer hydrogenation is known for many components; however, the most extensively studied ones are contributions towards reactions of carbonyl compounds alkenes and alkynes. These transformations have extreme relevance from mechanistic aspects and synthetic viewpoints as well. Transfer hydrogenations are selective reactions in most cases, and no side reactions are observed. As was stated above, since we have to tackle a redox equilibrium in order to achieve acceptable TOF values, the equilibria must be shifted to the product site. This goal can be reached with the fulfillment of the Le Chatelier-Braun principle, with the usage of excess amounts of the donor species, or by removing the oxidation product.

In general, transition metals in the reduction of carbonyls via transfer reactions are more active than the MPVO catalysts. For the reduction of ketones and aldehydes, alcohols and amines are used most generally, while cyclic ethers and hydroaromatic components are frequently used to reduce alkenes and alkynes. The saturation of the carbon-carbon double bonded and carbon-carbon triple bonded molecules is generally preferred to be carried out with molecular hydrogen. However, the wide range of active and selective transfer hydrogenation catalysts and the practicality of the procedure makes transfer hydrogenation a fair competitor of pathways when using molecular hydrogen as the H-source.

\subsection{Catalysis with Noble Metals}

\subsubsection{Hydrogen Transfer with Rhodium}

The Wilkinson complex $\left(\mathrm{Rh}\left(\mathrm{PPh}_{3}\right)_{3} \mathrm{Cl}\right)$ is very well known as a hydrogenation catalyst with molecular hydrogen, moreover, it was observed that it is an excellent transfer hydrogenation catalyst as well. The corresponding reaction mechanism strongly depends on the donor molecule. In the absence of molecular hydrogen, the intermediate metal complexes showed a four-coordinated square-planar configuration (Scheme 2) [1,39].

Detailed mechanistic investigations indicated that in the presence of 2-propanol as the hydrogen source, a single hydride was transferred from the $\alpha$-position of the donor to the $\alpha$-position of the acceptor $[1,39]$. The first step of the reaction is a rapid exchange of the halide ion to the alkoxide, followed by the formation of the 16-electron complex (Scheme 2) (5), the reactive monohydride species. The substrate (the corresponding keto material (6)) substitutes one of the ligands and coordinates to the catalytic center (formation of compound 7), followed by its insertion into the metal hydride bond (metal alkoxide formation, compound 8). The upcoming ligand exchange step (alkoxide (8) to ligand) yields the alcohol product (9). In the final elimination step of acetone, the catalytically active monohydride species forms (5).

For the saturation of alkenes and alkynes via hydrogen transfer reaction, in most of the cases, dioxane (11) provides the necessary H-source (Scheme 3) [1,34]. 


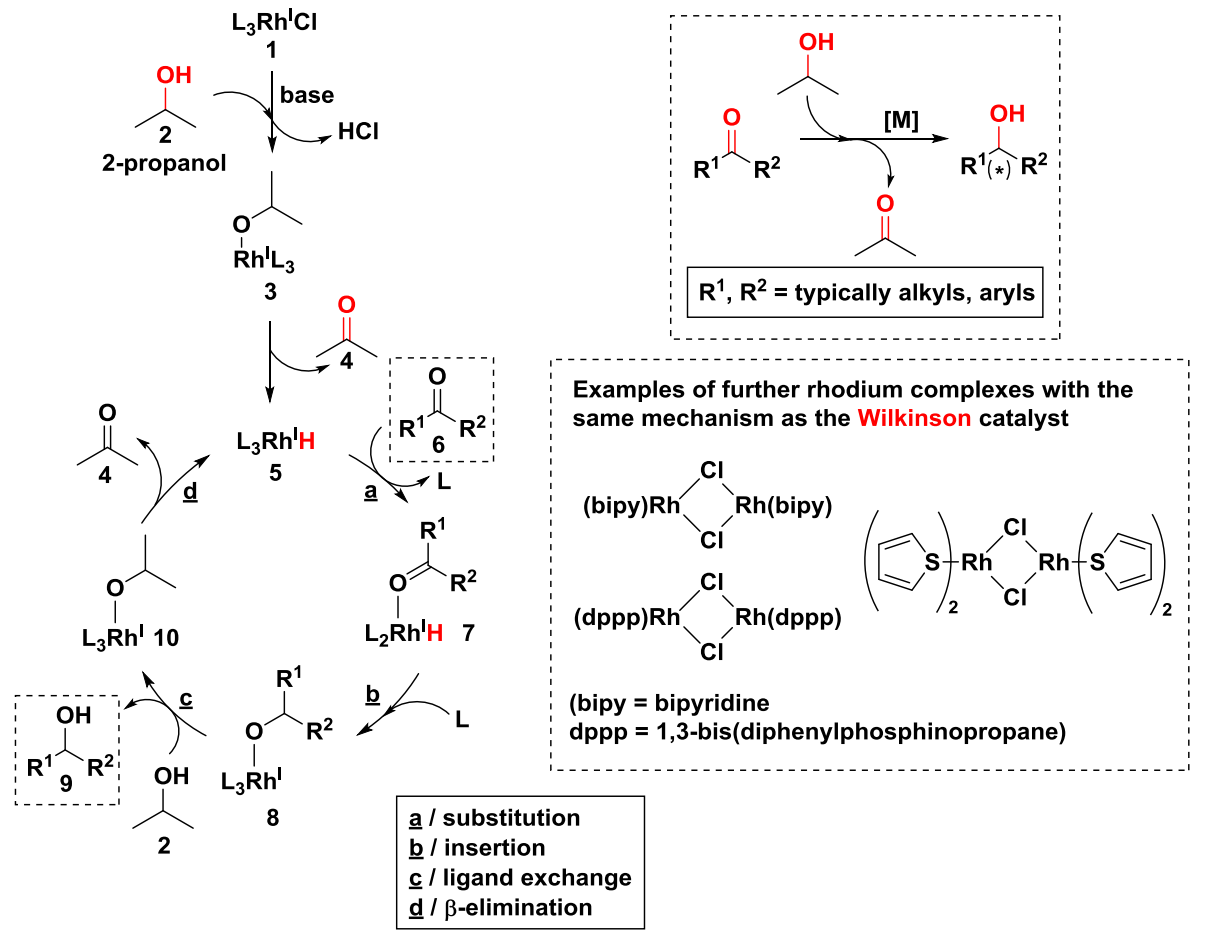

Scheme 2. Rhodium-catalyzed hydrogen transfer of carbonyl compounds in the presence of 2-propanol as a hydrogen donor.

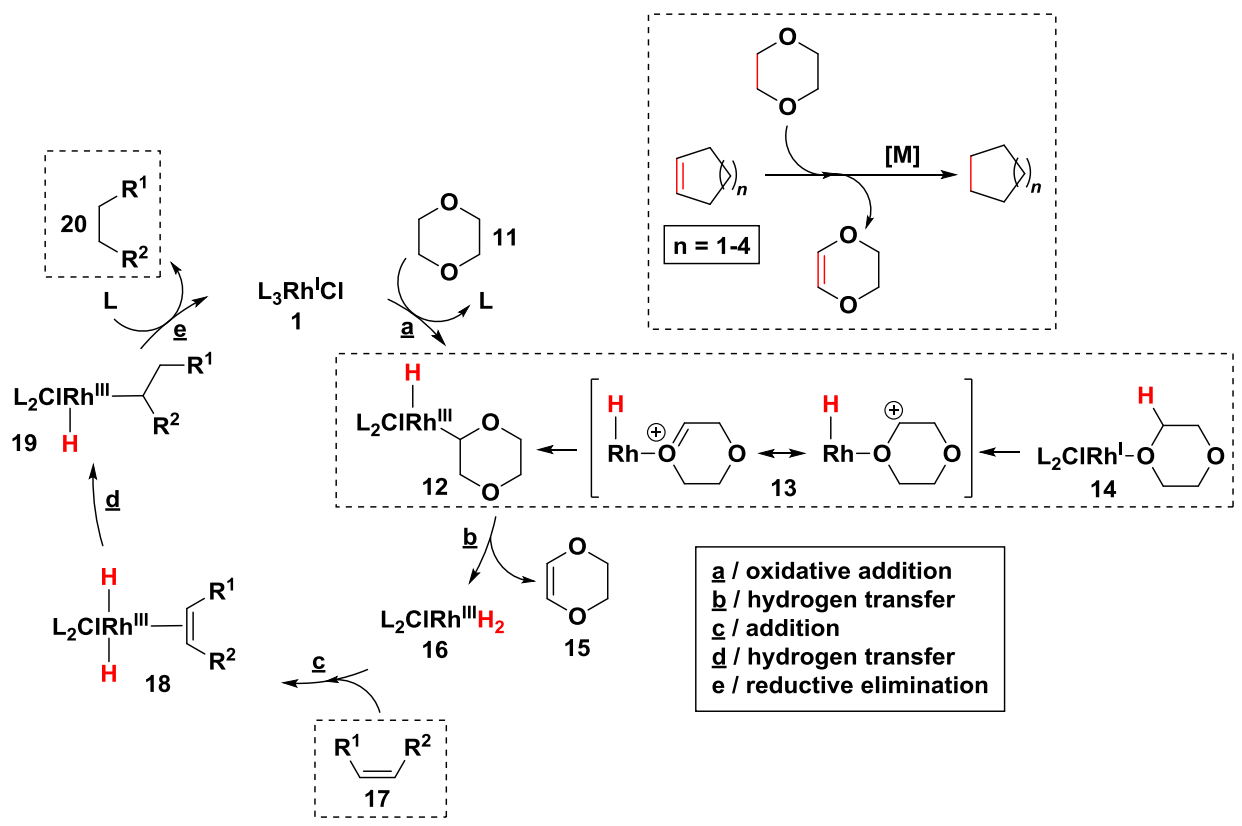

Scheme 3. Rhodium-catalyzed hydrogen transfer of alkenes in the presence of 1,4-dioxane as a hydrogen donor.

In the first step of the reaction, oxidative addition takes place (Scheme 3, step a), afterwards $\beta$-elimination leads to the formation of the 16-electron dihydride complex (16), as a consequence of the hydrogen transfer process to the unsaturated 2,3-dihydro-1,4-dioxine (15). After the coordination of the alkene substrate (17) to the empty site of $\mathbf{1 6}$ (formation of 18) a hydride insertion takes place, leading to the formation of complex 19. The reductive elimination step of the alkane (20) closes the catalytic cycle, while the ligand coordination restructures the $\mathrm{L}_{3} \mathrm{Rh}^{\mathrm{I}} \mathrm{Cl}(\mathbf{1})$ system. An interesting aspect of the catalytic cycle is the coordination and the oxidative addition of the H-source (Scheme 3, step a). 
It was proposed that the oxygen atom of the dioxane coordinates at first to the rhodium (14), while in the subsequent step, hydrogen abstraction takes place. The charged species (13) then rearranges and produces a carbon atom-linked complex (12).

Asymmetric reduction has great relevance in chemistry, in terms of the saturation reactions of carbonyls, alkynes and alkenes. Nowadays, asymmetric transfer hydrogenation (reductive route) has gained the noticeable position of second in the rank of importance, right behind the asymmetric hydrogenation reaction with molecular hydrogen. The success of this reaction type has promoted research directions to tackle more and more challenging issues, and the birth of many new catalysts/catalyst systems with increased catalytic activity and selectivity. Rhodium-, iridium- and a metal with the broadest scope, ruthenium-based systems (see Section 2.2.2) have a clear dominance as a metal source in asymmetric hydrogen transfer reactions. Since this field of research is very dynamic, only some representative findings and some unusual examples, which are within the purview (donor and acceptor molecules) of the present summary, are discussed.

The success of a catalyst dealing with asymmetric challenges depends on the design of the ligand as well. Hydrogen transfer reduction reactions may contain anionic or neutral ligands with bi-, tri-, or tetradentate binding capability. The most successful catalyst systems (in terms of activity and enantioselectivity) in the reduction of ketones to alcohols are the half-sandwich $\pi$-complexes.

Noyori et al. studied the asymmetric transfer hydrogenation of aromatic ketones and imines to chiral alcohols and amines in the presence of a chiral diamine-based $\mathrm{Ru}(\mathrm{II})$ catalyst (for a more detailed description, see Section 2.2.2.) [40]. A metal/ligand bifunctional effect (formation of a six-membered cyclic transition state stabilized by hydrogen bonding between the NH function of the ligand and the unsaturated $C=X$ moiety $(X=O, N R)$ of the substrate $[40,41])$ was described, together with exceptionally high enantiomeric purities [40]. The scope of their studies was further extended to rhodium and iridium complexes as well [42]. Acetophenone and its substituted derivatives as model compounds were studied in 2-propanol with $\mathrm{KO}^{t} \mathrm{Bu}$ at $30^{\circ} \mathrm{C}$ [42]. Similarly, as was observed previously for the ruthenium counterparts, depending on the ketone substrate, moderate to high conversions and excellent ee (\%) (enantiomeric excess) values were determined (Scheme 4) [42].

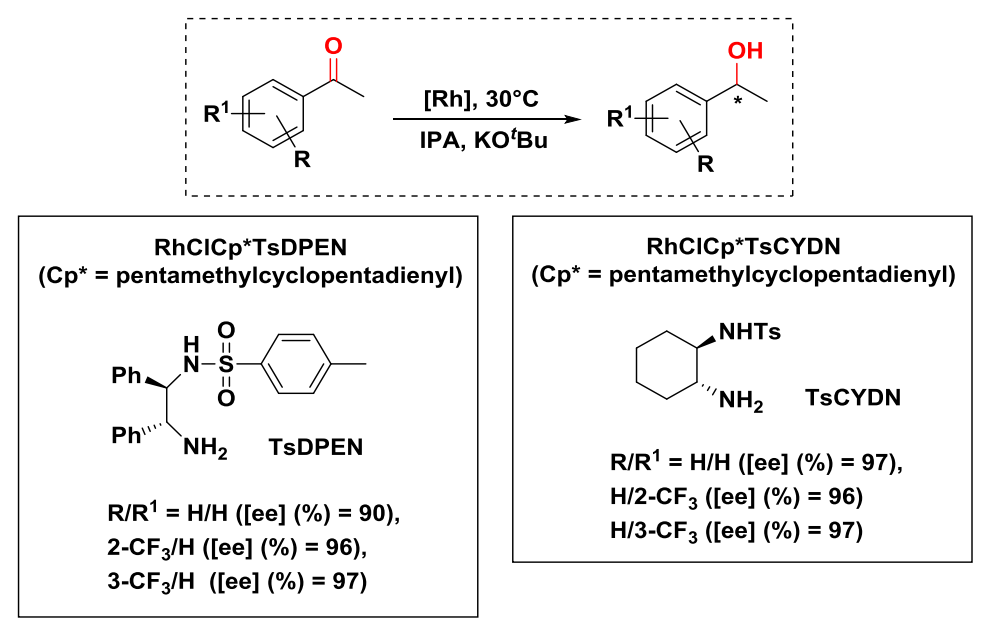

Scheme 4. Rhodium-catalyzed asymmetric transfer hydrogenation of carbonyl derivatives.

Aryl and alkyl carbonyls were converted in a hydrogen transfer reaction with good yields to the corresponding alcoholic species in the presence of air-stable $\left[\mathrm{Rh}^{\mathrm{III}}\right.$ (bis-carbene) $\left.\mathrm{I}_{2}(\mathrm{OAc})\right]$ complexes (hydrogen transfer of imines to amines was observed as well) (Scheme 5) [43]. The complex with the iso-propyl function hydrogenated the aliphatic substrates faster than the aromatic ones. The C,C-bidentate chelating binding mode of the NHCs ( $\mathrm{N}$-heterocyclic carbenes) was evidenced by detailed NMR spectroscopic investigations (Scheme 5) [43]. 


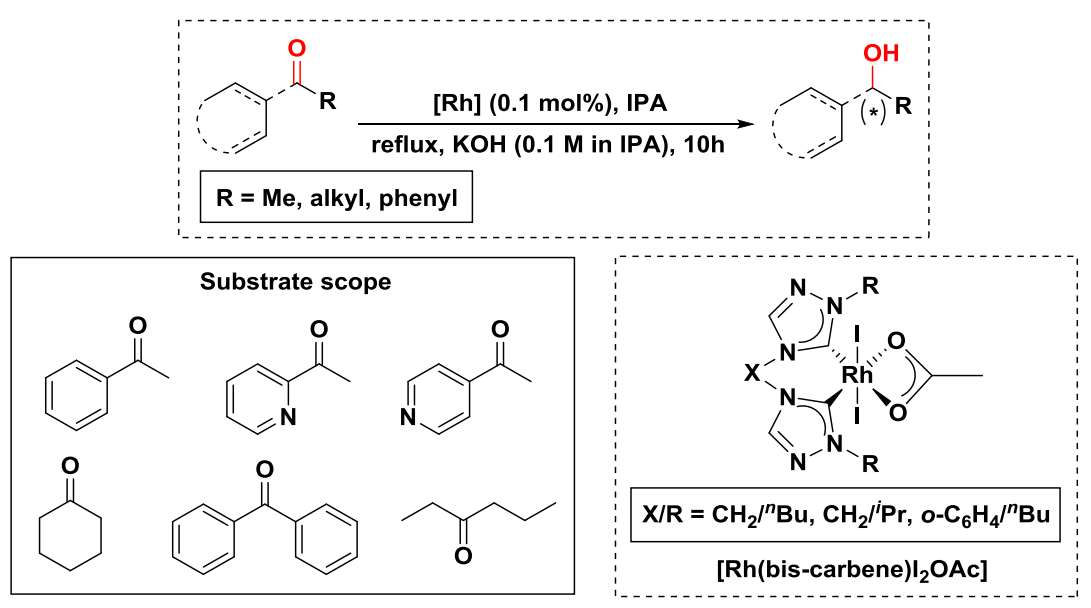

Scheme 5. Transfer hydrogenation of ketones with chelating bis-carbene rhodium complexes.

The almost endless variability can be seen very clearly on the wide range of the newly developed Rh-based catalysts systems. On Scheme 6, several newer achievements are summarized.

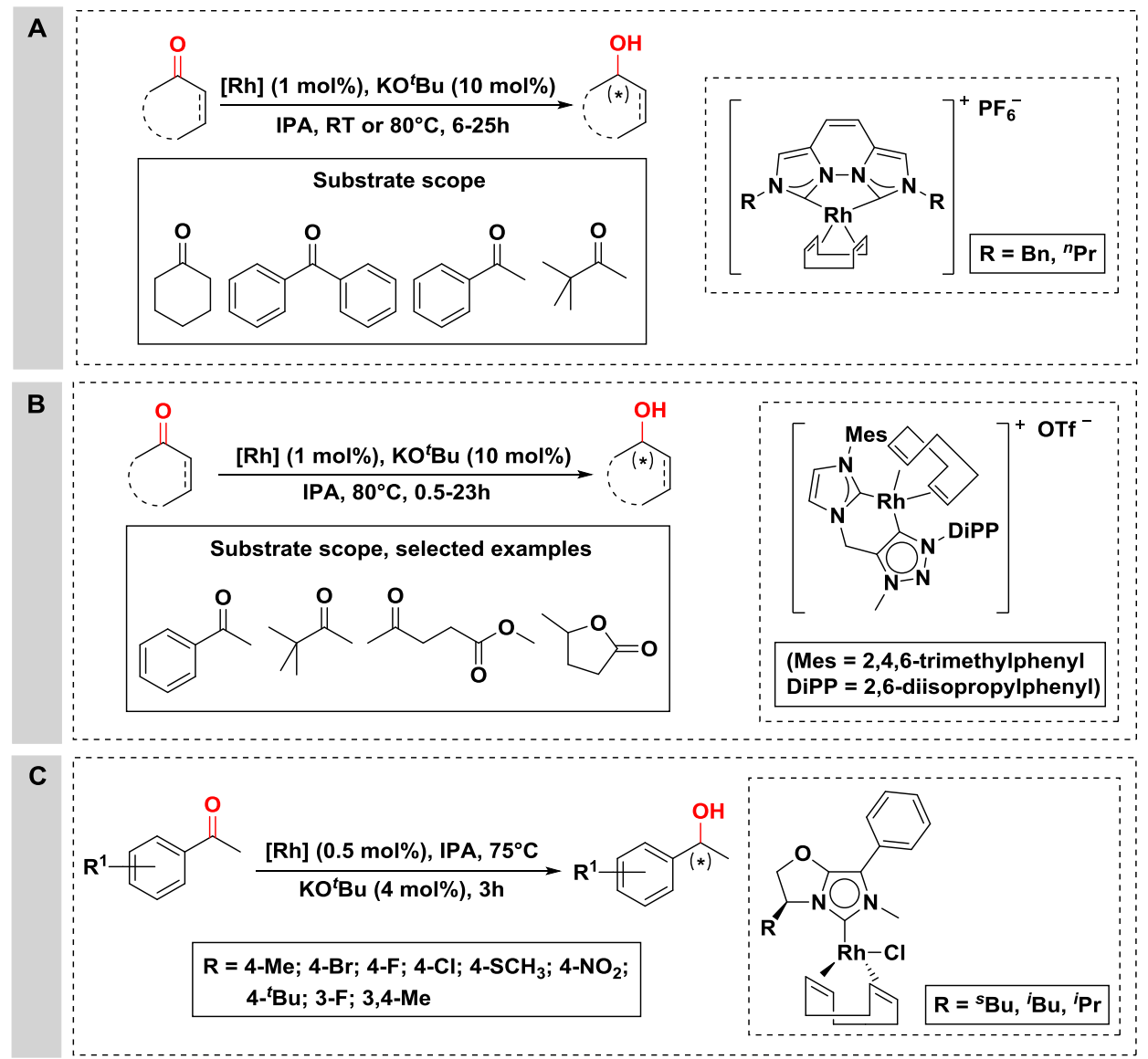

Scheme 6. Rhodium-catalyzed asymmetric transfer hydrogenation in the presence of 2-propanol as a H-donor. Reactions with pyridazine annelated bis(NHC) ligand (A), with dicarbene tzNHC-NHC derivatives (B), chiral oxazolidine-fused NHC ligands (C). (RT = room temperature).

A pyridazine-annelated bis(NHC) ligand with benzyl substituents was reported, as well as its corresponding Rh complex (Scheme 6, equation A) [44]. The mechanism of the formation of the cationic rhodium complex were investigated, a stepwise deprotonation of the imidazolium moieties via a mono-carbene imidazolium species was observed. The catalytic activity of the new "vegi"-type 
complexes was studied; the cyclic alcohol products were synthesized with good-to-excellent yields (81-99\%), depending from the substrate used [44].

Continuing the success of the NHC-type ligand family, a series of cationic chelate rhodium complexes (iridium as well) have been synthesized, bearing a mixed 1,2,3-triazol-5-ylidene (tzNHC)-NHC moiety (Scheme 6, equation B) [45]. The dicarbene tzNHC-NHC derivatives showed significantly higher catalytic activities in the comparison with the ones with one NHC and a secondary nitrogen donor. The various substituents on the tzNHC moiety did not have remarkable impact on the catalytic activity. Moderate yields were obtained in the presence of rhodium-based catalysts (23-98\%) [45].

Asymmetric transfer hydrogenation was studied with chiral oxazolidine-fused NHC ligands with rhodium (and iridium) as the metallic part (Scheme 6, equation C) [46]. The multistep synthesis protocol does not require any enantiomeric separation step, and starts from commercially available optically pure amino acids. The rhodium(I) complexes showed wide applicability towards differently substituted aromatic ketones as starting materials. The desired alcohols were synthesized with moderate to good yields (18-95\%), but with low enantioselectivites (ca. 4-41\%) [46].

Cyclometalated rhodium complex (Scheme 7) was highly active in the hydrogen transfer reaction of aldehydes to the corresponding alcohol in the presence of methanol as the hydrogen source [47]. More than 35 examples indicated the wide applicability of the system, and substituted cyclic aldehydes and heterocycles with aldehyde function was converted, with high yields $(71-91 \%)$ at $90^{\circ} \mathrm{C}$ in methanol as hydrogen donor, and solvent to the alcoholic species (Scheme 7) [47].

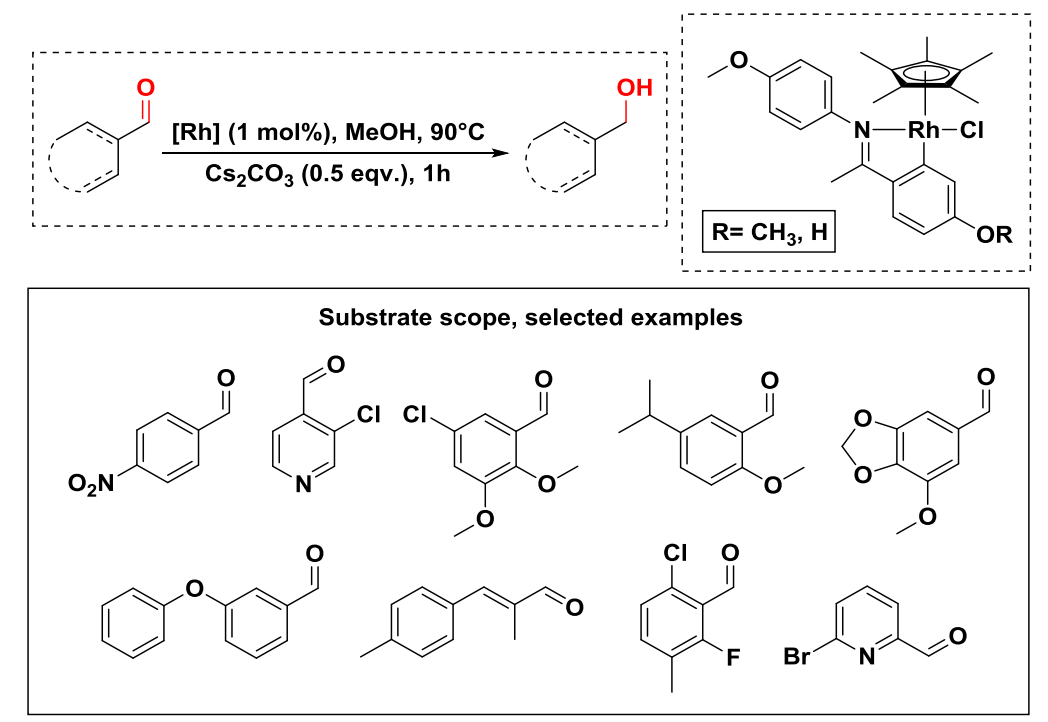

Scheme 7. Transfer hydrogenation of aldehydes with rhodacycles.

Rhodium(III) complexes, having both a cis-chelating dicarbene (dicarbene/methylene $\left(4,4^{\prime}\right.$ diimidazolydene) and a diphosphine ligand (diphosphine/(R)-(+)-2,2'-bis(diphenyl- phosphino)-1,1'binaphtalene ((R)-BINAP); 1,2-bis(diphenylphosphino)-ethane (dppe)) were synthesized and tested in the hydrogen transfer reaction of aromatic ketones, with IPA as the donor molecule (Scheme 8) [48]. It was observed that the presence of the diphoshpine ligand increased the catalytic activity of the rhodium center drastically, and 4000 TONs (turnover numbers) and TOFs $\sim 1000 \mathrm{~h}^{-1}\left(\sim 330 \mathrm{~h}^{-1}\right.$ for the phosphine-free counterpart) was measured. The process that was used tolerated the presence of water, and instead of the typical $10 \mathrm{~mol} \%$ of a base, only $1 \mathrm{~mol} \%$ was used. During the ligand design, it was noticed that the BINAP ligand was not oxidized; however, dppe was less stable; dppe oxide was formed, as witnessed by NMR spectroscopy, and there was an indication of some lability of the ligand in the condensed phase. Most probably, the lability of the dppe ligand was promoted by the strong trans effect of the carbene donor (Scheme 8) [48]. 


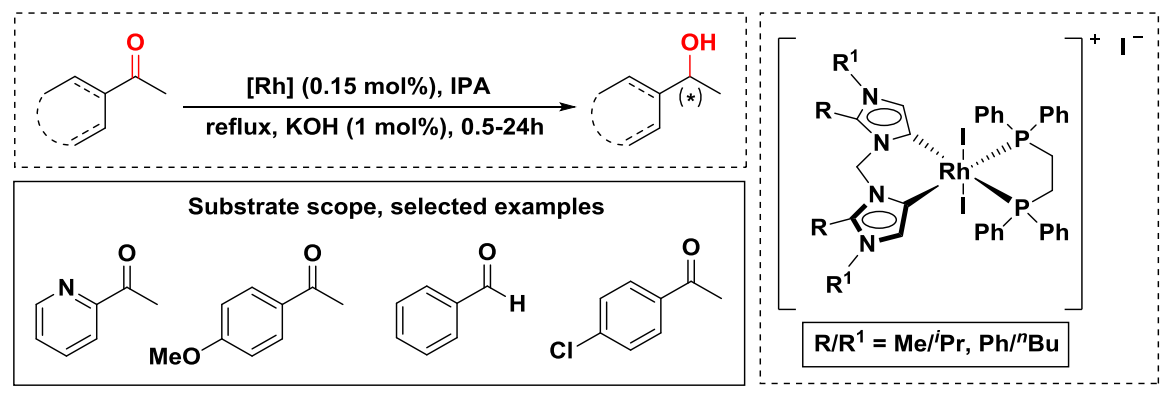

Scheme 8. Transfer hydrogenation of rhodium(III) complexes with both chelating dicarbenes and diphosphine ligands.

\subsubsection{Hydrogen Transfer with Ruthenium}

A further solution of hydrogen transfer for the reduction of ketones to alcohols is to use the 16-electron complex of $\mathrm{Ru}\left(\mathrm{PPh}_{3}\right)_{2} \mathrm{Cl}_{2}$ (Scheme 9) [1,33,39,49]. Within the first step of the reaction, the dichloride complex (21) rapidly converts into the corresponding dihydride species (22), similarly as was previously described for the Wilkinson complex (monohydride route, Scheme 1), but with the formation of a dihydride-type complex. In the upcoming step the monohydridic alkoxide species forms (23) followed by the reductive elimination (Scheme 9, step b) giving the product (9) and a $\mathrm{Ru}^{0}$ complex (24). The oxidative addition of the hydride donor functioning alcohol molecule (2) produces complex 25, and the result of the next $\beta$-elimination step (Scheme 9, step d) leads to the formation of the $\mathrm{Ru}^{\mathrm{II}}$ dihydride complex again (22).

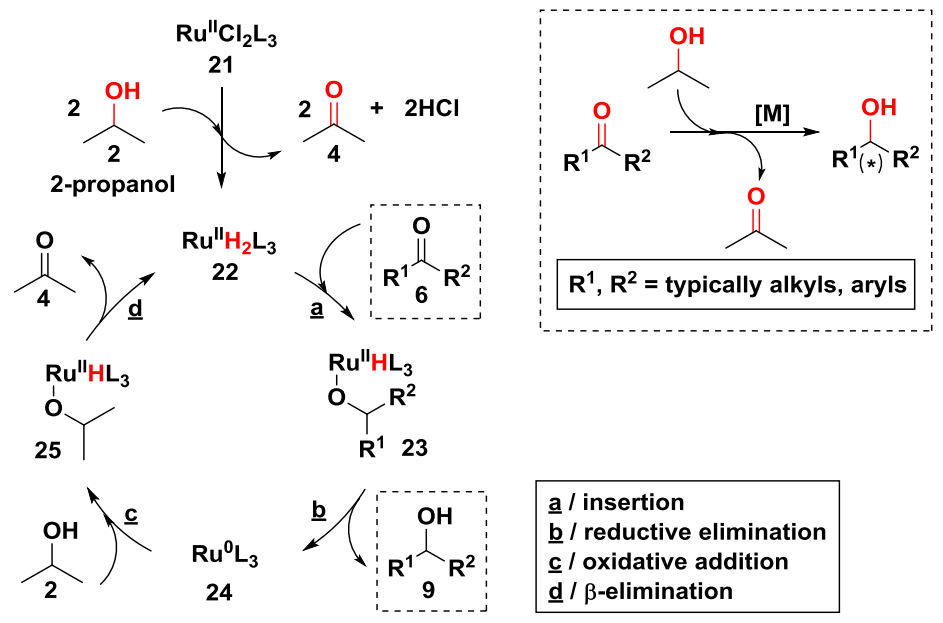

Scheme 9. Ruthenium-catalyzed hydrogen transfer with alcohols, dihydride mechanism (innersphere pathway).

It was observed that one way to increase efficiently the rates of the reductive hydrogen transfer reactions in the presence of transition metals, was to introduce a small amount of base molecules into the reaction mixture [17-19,50]. Another solution to tackle this challenge was to build a basic site additionally into the catalysts (Scheme 10) [1,51-53]. The 16-electron Ru complexes with a basic nitrogen atom in their structure such as complex 26, showed remarkable catalytic activity, as studied by Noyori and other researchers [51-53]. In the presence of complex $\mathbf{2 6}$ a concerted-type hydride shift takes place involving a six-membered transition state (27) [51-53]. The hydroxyl proton of the donor molecule (2) is abstracted by the basic nitrogen atom of the ligand, while the hydrogen in the $\alpha$-position of the alcohol is shifted to the metal in a concerted-type pathway (Scheme 10, step b), liberating a ketone (4). Complex 28 reacts with the acceptor substrate (6) and forms complex 29, in the upcoming transfer step, the product (9) eliminates from complex 29, and restores the 16-electron ruthenium species (26). 


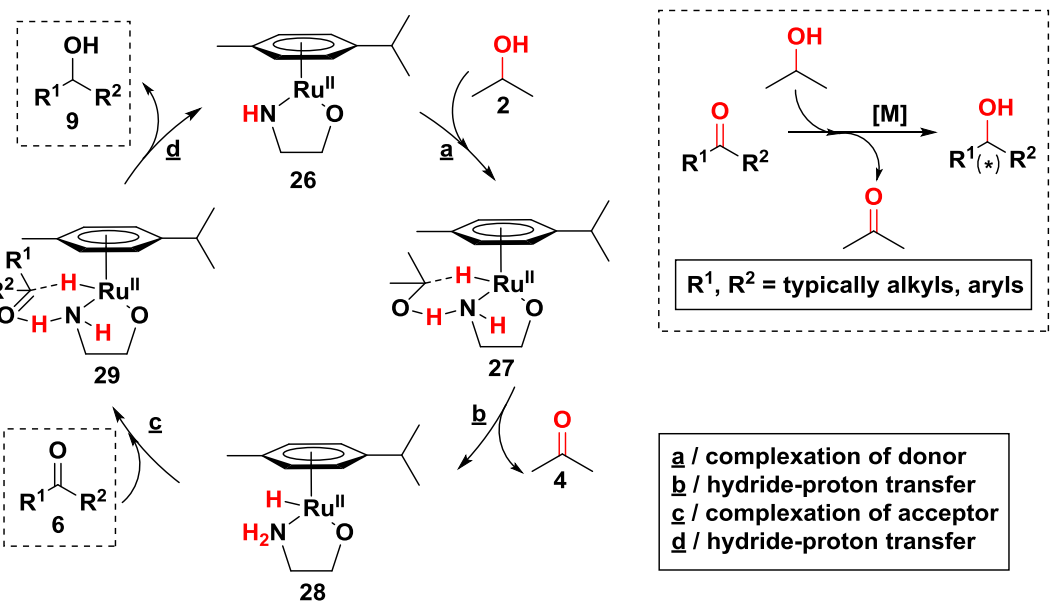

Scheme 10. Ruthenium catalyzed hydride-proton transfer, concerted (outer-sphere pathway) mechanism.

The Ru-arene system (Scheme 10, complex 26) (and Rh- or Ir-cyclopentadienyl complexes), such as Noyori's catalyst, contains 1,2-amino alcohols or monotosylated diamine ligands (in some cases phosphine-oxazoline derivatives) in their structure, a combination that leads to a catalyst system with the broadest substrate scope (Figure 2) [28,54]. It was observed that the presence of the $\eta^{6}$-arene moiety is essential for the success of the behavior of the catalysts, due to its stabilizing ability of the transition state by $\pi$-interactions (Figure $2 /$ benzene $(\mathbf{1}) / \mathrm{C}\left(\mathrm{sp}^{2}\right) \mathrm{H} / \pi$, alkylated arenes $(\mathbf{2}) / \mathrm{C}\left(\mathrm{sp}^{3}\right) \mathrm{H} / \pi$ ). With the investigation of a series of monotosylated diamines with different configurations in the hydrogen transfer reaction of acetophenone, a better understanding of the enantiocontrol of Noyori's complex was provided [54]. Ruthenacycles (with tethered structural motif and with chiral diphosphine or chiral pyridine as ligands) showed high activity and enantioselectivity in the reduction of aryl alkyl ketones ([ee]/(\%): 87-94) [55-57].
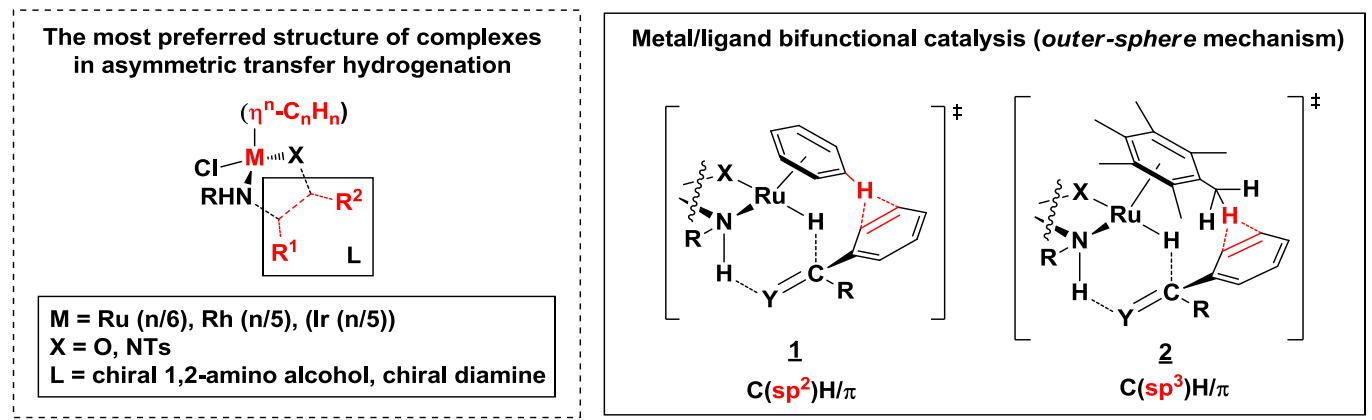

Figure 2. Complex structures, stabilization via $\pi$-donation (outer-sphere pathway).

The success of the $\mathrm{Ru}$-arene system with the variety of different ligands can be seen clearly in the huge amount of results that have been reported $[1,21,28]$. Several results towards the reduction of acetophenones (Scheme 11) and acylbenzenes (Scheme 12) obtained with $\mathrm{RuCl}_{2} \mathrm{PPh}_{3}$ (oxazferrphos) [58-60], $\mathrm{RuCl}(1,4-c y m e n e)($ prolinamide) [58-60], RuCl(hexamethylbenzene)(azanorbornylmethanol) [61], and with $\mathrm{RuCl}(1,4-c y m e n e)(a z a n o r b o r n y l m e t h a n o l)$ [59,60,62], is depicted in Schemes 11 and 12.

In Scheme 13, three interesting cases are pointed out. $\alpha, \beta$-Unsaturated carbonyl derivatives could be reduced to the corresponding alcohol species, because the reaction proceeds preferentially in the carbonyl fragment. 4-Hydroxyisophorone has been synthesized with higher than $95 \%$ ee in the presence of [ $\mathrm{RuCl}_{2}\left(\eta^{6}\right.$-arene)(chiral 1,2-amino alcohol)] (Scheme 13, equation A) [63]. 


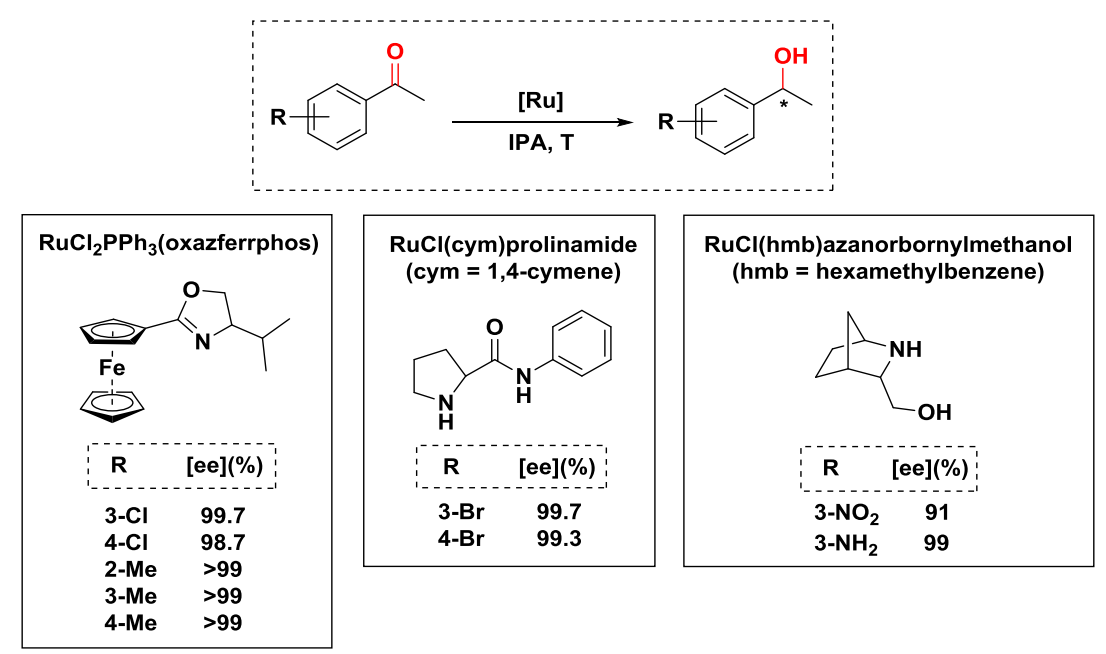

Scheme 11. Ruthenium-catalyzed asymmetric transfer hydrogenation of substituted acetophenones, ( $\mathrm{T}=$ corresponding reaction temperature.)

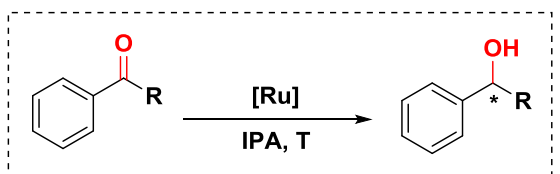

\begin{tabular}{|cc|}
\hline $\mathrm{RuCl}_{2} \mathrm{PPh}_{3}$ (oxazferrphos) \\
\hdashline $\mathrm{R}$ & {$[\mathrm{ee}](\%)$} \\
\hdashline${ }^{n} \mathrm{Bu}$ & 98.7 \\
${ }^{t} \mathrm{Bu}$ & 93 \\
$\mathrm{Et}$ & 99.7 \\
\hline
\end{tabular}

RuCl(cym)azanorbornylmethanol (cym = 1,4-cymene)

\begin{tabular}{lll} 
& $\mathrm{R}$ & {$[\mathrm{ee}](\%)$} \\
\hdashline${ }^{n} \mathrm{Pr}$ & 92 \\
${ }^{i} \mathrm{Pr}$ & 90 \\
${ }^{n} \mathrm{Hex}$ & 95
\end{tabular}

Scheme 12. Ruthenium-catalyzed asymmetric transfer hydrogenation of acylbenzenes, $(\mathrm{T}=$ corresponding reaction temperature).

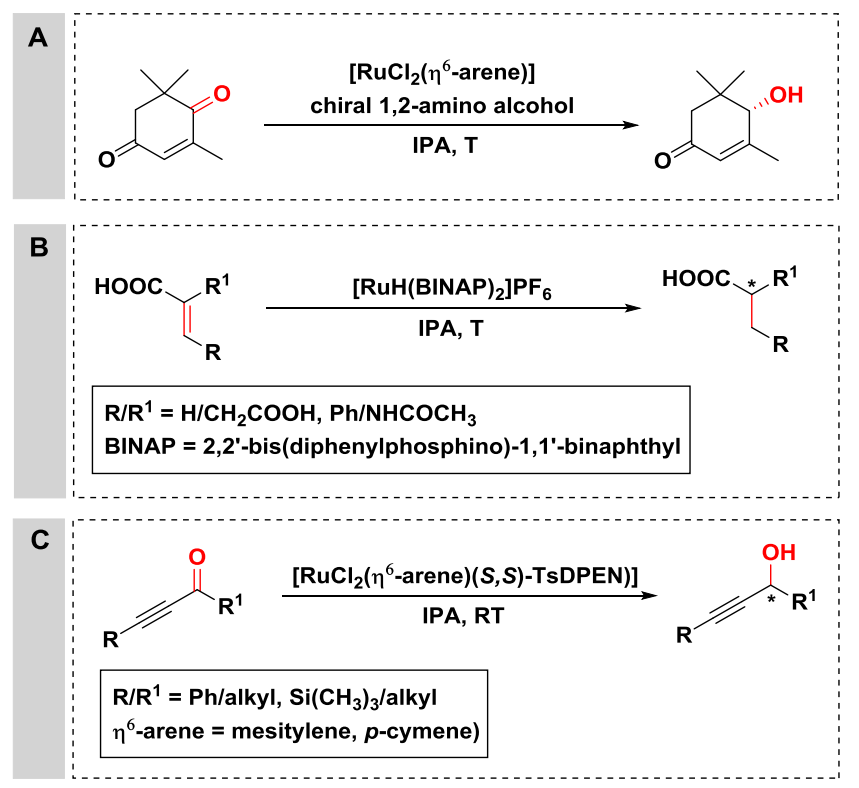

Scheme 13. Ruthenium-catalyzed asymmetric transfer hydrogenation in the presence of 2-propanol as a H-donor for ketoisophorone (A), conjugated carboxylic acids (B), and ethinyl ketones (C), ( $\mathrm{T}=$ corresponding reaction temperature, $\mathrm{RT}=$ room temperature). 
Conjugated carboxylic acid derivatives such as itaconic acid and $\alpha$-acetamidocinnamic acid were reduced to their saturated form, with higher than $90 \%$ ee (Scheme 13, equation $\mathbf{B}$ ). The reaction was selective, and only the corresponding saturated carboxylic acids were detected [63].

Conjugated aryl- and alkyl ethinyl ketones were reduced to the unsaturated alcoholic derivatives with higher then $95 \%$ ee, independent of the bulkiness of the substituent linked to the carbonyl moiety, with the usage of Noyori's catalyst (Scheme 13, equation C) [64,65]. Silylated terminal ethinyl ketones were easily converted to the desired propargylic alcohols with constantly high ee values as well. The $\mathrm{C} \equiv \mathrm{C}$ triple bond of the model substrates was inert under identical reaction conditions.

When 2-propanol is the hydrogen donor molecule, a base usually has to be added to the reaction mixture in order to activate the starting complex. In most of the cases of hydroxides or alkoxides, sodium or potassium carbonates are used, with different concentrations. There exists only very few catalyst precursors that do not require the presence of such basic species. One of them is the Shvo catalyst (Scheme 14) [1,66-69].

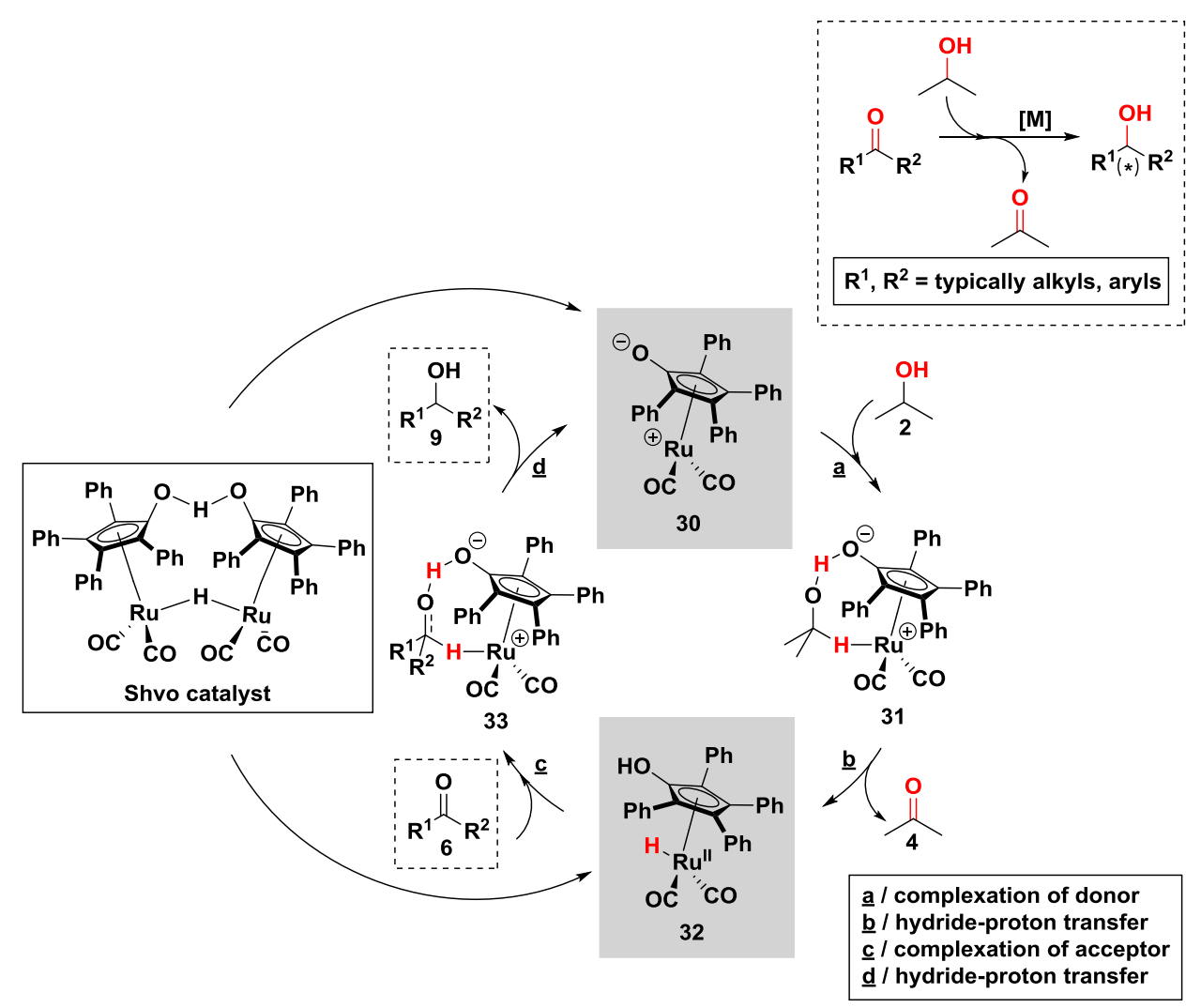

Scheme 14. Transfer hydrogenation with the Shvo catalyst, via the concerted hydride-proton pathway.

The Shvo catalyst is a dinuclear Ru complex, which converts to two mononuclear Ru species (30 and 32) under reaction conditions (the pre-catalyst is in equilibrium with complex 30 and 32) (Scheme 14) [70-72]. Both of the intermediates react similarly (concerted-type hydride-proton shift), via the formation of the six-membered transition state (31) and the reduction of the ketone (6) via 33 giving the product (9).

Instead of 2-propanol, primary alcohols such as ethanol can be used as hydrogen source as well, for transfer hydrogenation reactions [73]. Despite the negative properties (such as ability to form stable carbonyl complexes, and the formation of condensation products between the acetaldehyde and the ketone substrate) which can be circumvented, ethanol as a possible donor and a solvent molecule was studied in asymmetric hydrogen transfer reactions of aryl alkyl ketones at $40^{\circ} \mathrm{C}$ in the presence of the combination of $\left[\mathrm{Ru}(p \text {-cymene }) \mathrm{Cl}_{2}\right]_{2}$ and amino acid hydroxy-amide (Scheme 15) [73]. The secondary 
alcohol products were obtained with moderate to good yields (59-99\%), and with good to excellent enantioselectivity (up to $97 \%$ ) [73].

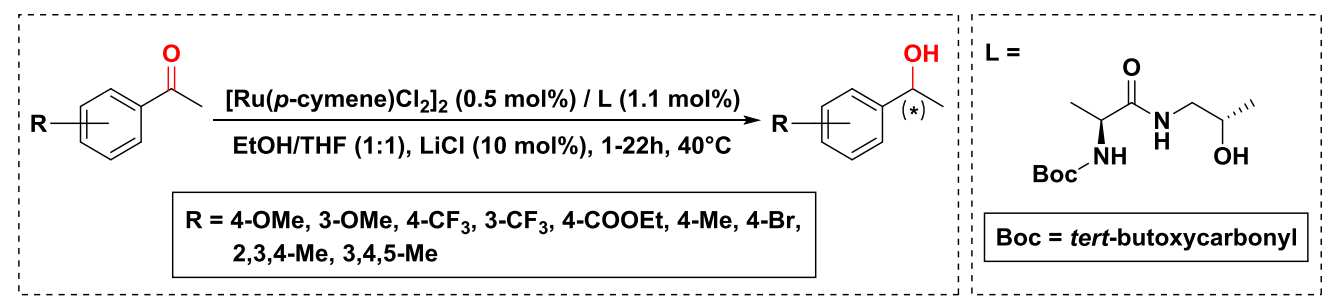

Scheme 15. Asymmetric transfer hydrogenation with ruthenium, combining with amino acid-based ligands.

Ruthenium complexes with CO ligand(s) were reported as active catalysts in the transfer hydrogenation reaction of ketones [74,75]. Cyclometalated dicarbonyl complexes such as 34, 35, and 35a-35c (Scheme 16) catalyzed the transfer hydrogenation of acetophenone in 2-propanol as a hydrogen source in the presence of alkali base (1-5 mol \%) at reflux conditions (TOF up to $30,000 \mathrm{~h}^{-1}$ ) [74]. Mechanistic considerations showed that the [Ru-H] complex most probably forms from the corresponding $\left[\mathrm{Ru}-\mathrm{O}{ }^{i} \mathrm{Pr}\right]$ complex via $\beta$-hydrogen elimination (inner-sphere mechanism), while complexes having $\mathrm{NH}_{2}$ functionality in the $[\mathrm{Ru}-\mathrm{H}]$ complex form from a 16-electron Ru-amide [74,76] or from a Ru-amine/alkoxide species (outer-sphere mechanism) [74,77,78].

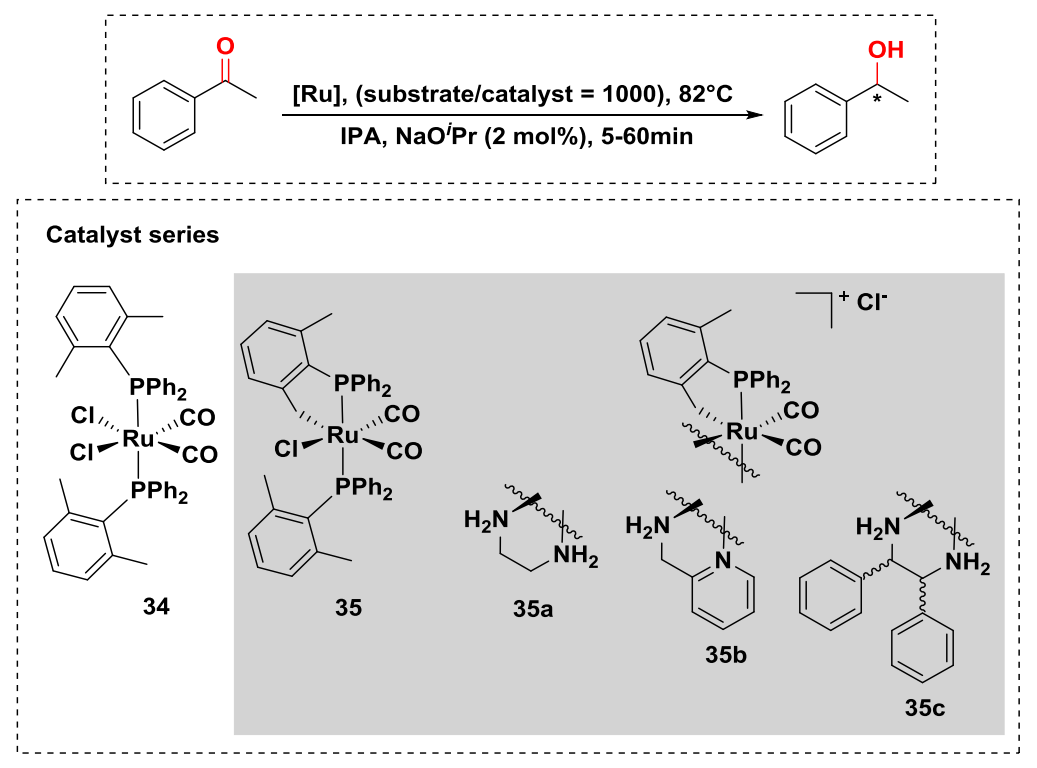

Scheme 16. Reduction of ketones via transfer hydrogenation with cyclometalated dicarbonyl ruthenium catalysts.

A series of cationic and neutral ruthenium(II) complexes with 4'-(aryl)-2,2':6',2"-terpyridyl- based ligands with various aryl groups (tolyl, phenyl, 4-fluorophenyl) were synthesized and characterized (Scheme 17) [79]. The newly synthesized catalyst series was successfully used in the transfer hydrogenation of ketones (yield/53-84\%, TON/106-172) with a wide substrate scope. The neutral complexes were catalytically more active than the cationic counterparts because of their reduction potentials $\left(E_{1 / 2}\right)$, which were lowered by $0.30 \mathrm{~V}$, promoting the reduction of ketones [79]. Based on the experimental results, the supposed mechanism is an inner-sphere reduction pathway, including the formation of a $[\mathrm{Ru}-\mathrm{H}]$ intermediate in 2-propanol as the hydrogen source (Scheme 9, Scheme 17). The presence of the $[\mathrm{Ru}-\mathrm{H}]$ complex was confirmed by ${ }^{1} \mathrm{H}$ NMR spectroscopy and by HR-MS analysis. 


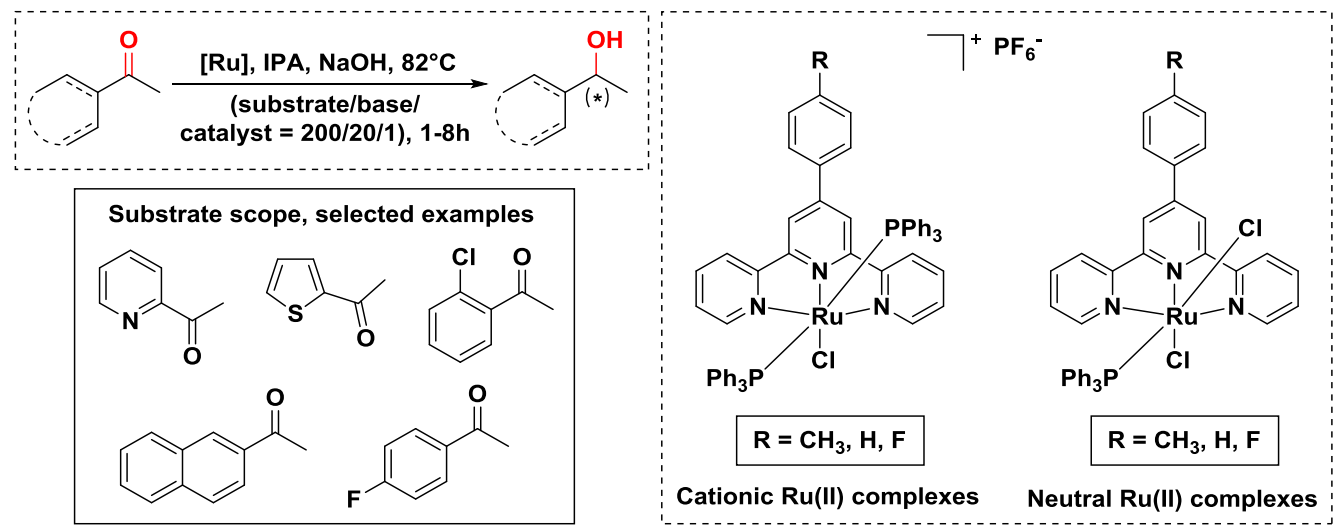

Scheme 17. Reduction of ketones via transfer hydrogenation in the presence of ruthenium(II) complexes with $4^{\prime}$-(aryl)-2,2':6', 2"'-terpyridyl ligands.

Ruthenium(II) complexes have gained remarkable attention during the past years, based on the robustness and high efficiency of these complexes. Transfer hydrogenation, catalyzed by ruthenium(II) complexes, have been developed from different aspects, such as the variety of the ligands. In Scheme 18, several additional contributions towards the synthesis of $N, N, N$-tridentate coordinating pincer-type ligands have been selected. The air- and moisture-stable ruthenium(II) complex, such as complex 36, was synthesized and used for the transfer hydrogenation of ketones in the presence of IPA under reflux conditions. Excellent activity was attributed to NH functionality, and to the hemilabile unsymmetrical coordination nature [80]. Complex 37 showed $99 \%$ yields to the desired alcohols, having a (trifluoromethyl)pyrazolyl functionality [81]. Under mild and aerobic reaction conditions, at room temperature with IPA as the hydrogen donor, ketones and aldehydes were converted to the corresponding products with complex 38 [82]. Complex 39 with symmetrical pyridyl-2,6-pyrazolyl ligand was highly active in the transfer hydrogenation of ketones with a wide structural variety in the presence of IPA as a hydrogen donor [83]. Similarly as complex 39, the symmetrical complex 40 showed high catalytic activity in the transfer hydrogenation of ketones; the results obtained for complex 40 surpassed those obtained for the cationic counterpart [84]. Complex 41, including 2,6-bis(oxazoline)-pyridine (pybox) ligand and a monodentate phosphite in its structure was used in the asymmetric transfer hydrogenation of acetophenones-derived $\mathrm{N}$-aryl imines [85]. Complex 42, with the rigid bifunctional 6,6'-dihydroxyterpyridine (dhtp), showed no activity in the transfer hydrogenation of bulky ketones [86]. The bifunctional complex 43 ( $\mathrm{Ru}(\mathrm{II})$-(phenpy-OH), phenpy-OH/2-(2-pyridyl-2-ol)-1,10-phenathroline) was highly active, and showed excellent conversion in the reaction of a wide range of ketones (and nitriles as well) as substrates with IPA as the hydrogen source [87].

The remarkable success of transfer hydrogenation reactions by the $N, N, N$-tridentate coordinating pincer-type ligand family was further proven by Albrecht et al. [88]. Pyridylidene amides (PYAs) were the choice of usage, because the stabilization of different metal electronic configurations can be applied without the chemical transformation of the ligand skeleton (Scheme 19) [88]. The combination of the pincer motif and the PYA donor system leads to ruthenium complexes with excellent activity and selectivity (Scheme 19) [88].

The catalytic activity and the electronic density at the ruthenium(II) center was tunable, based on the corresponding substitution of the ancillary ligands of the $\left[\mathrm{Ru}(N, N, N) \mathrm{L}_{3}\right]$ complex (Scheme 19). Increased catalytic activity was observed in the presence of phosphine ligands, and detailed mechanistic investigations showed that the origin of this enhancement is based on the lability of the MeCN ligand and the strong trans effect of phosphines (better substrate coordination and product release). For carbonyl substrates, up to $490 \mathrm{TOF}_{50}\left(\mathrm{hr}^{-1}\right)$ was measured, depending from the complex used (Scheme 19, equation A), while $\alpha, \beta$-unsaturated ketones such as the methyl cinnamylketone were completely converted to the saturated ketone (4-phenyl-2-butanone) within 30 min (Scheme 19, 
equation B). Selective transfer hydrogenation of $\alpha, \beta$-unsaturated carbonyl compounds with $\mathrm{Ru}$, Ir, and Fe complexes was currently summarized by de Vries et al. [89].

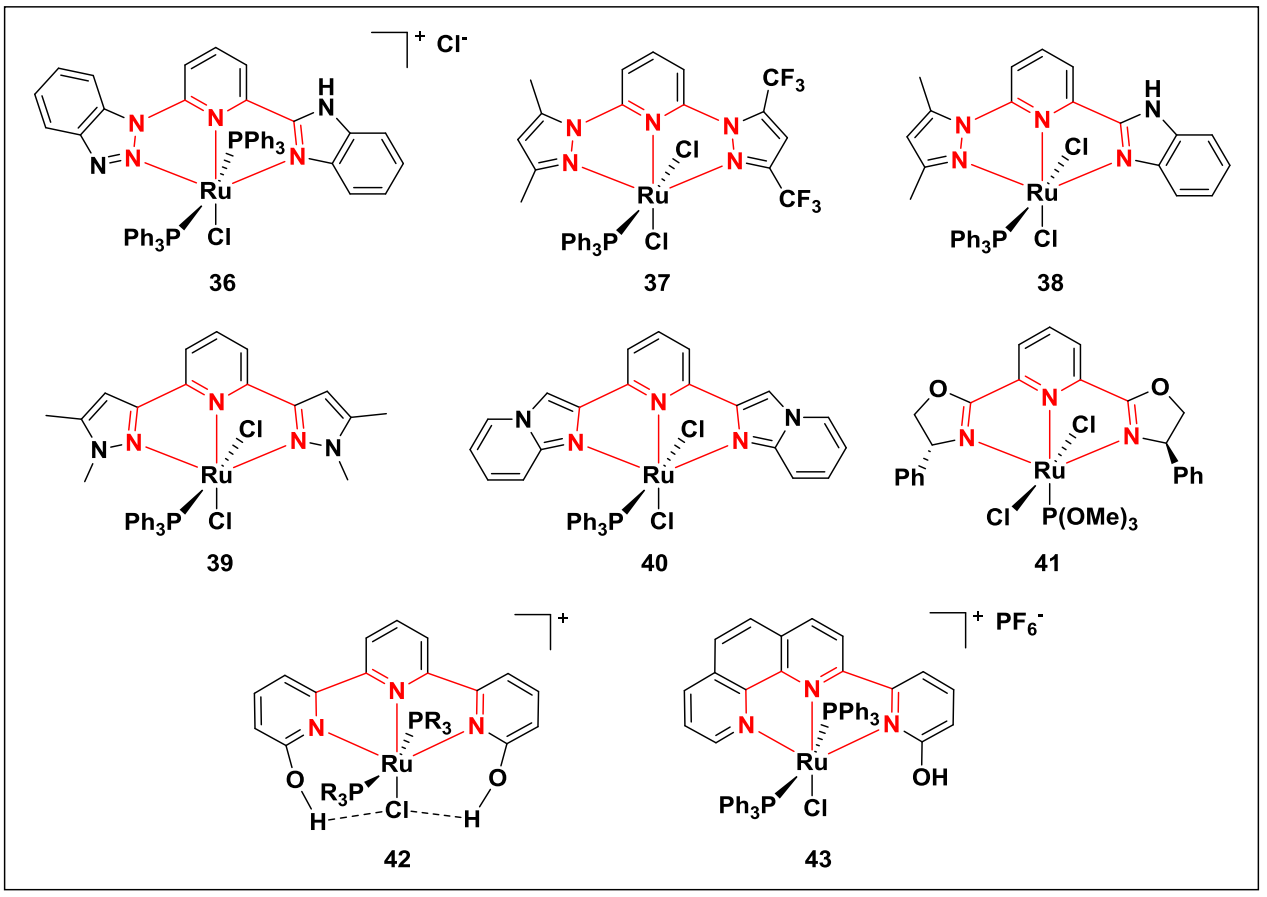

Scheme 18. Ruthenium(II) catalysts with $N, N, N$-type pincer ligands for transfer hydrogenation reactions.

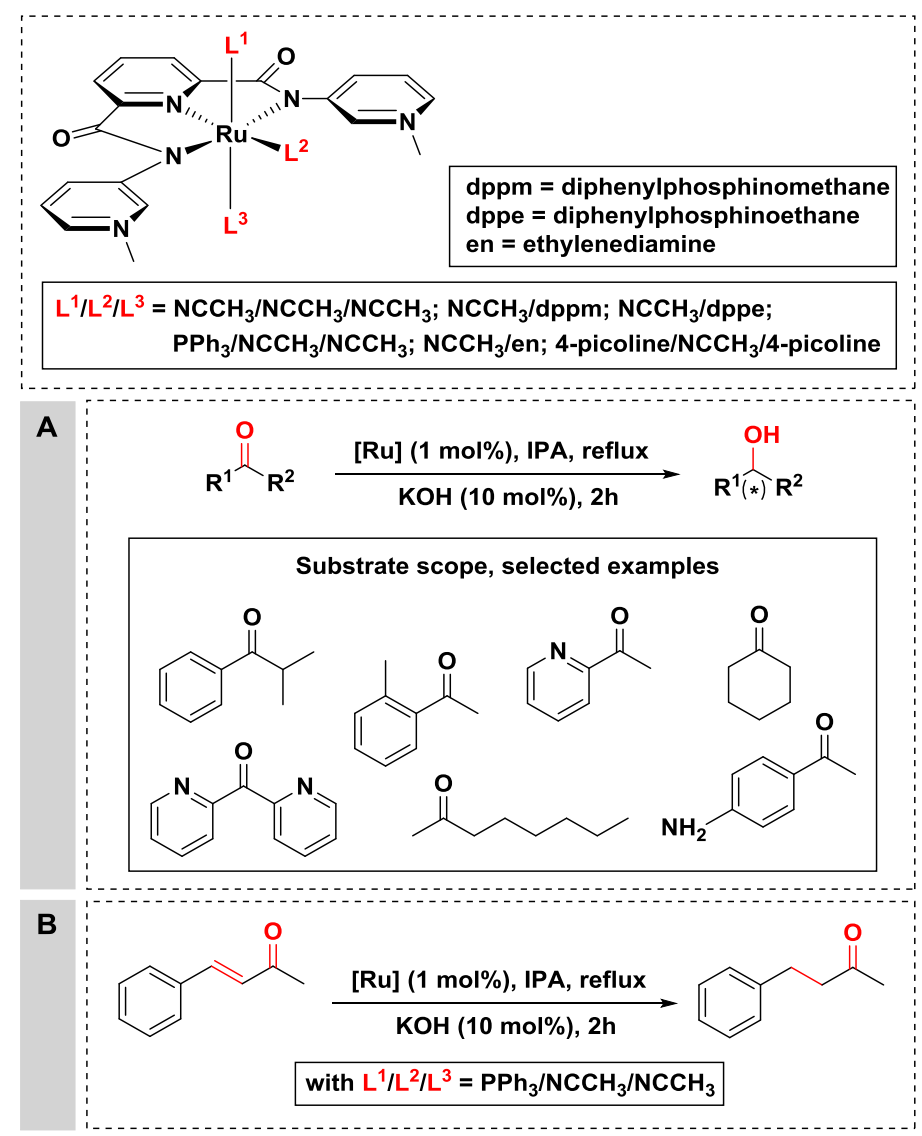

Scheme 19. Pyridylidene amide ruthenium(II) complexes for transfer hydrogenation. 
New ruthenium(II) complexes having pyrazole-phosphine ligands were synthesized and applied in transfer hydrogenation reactions of alkenes and alkynes (heterocyclic compounds, nitriles and esters as well) (Scheme 20) [90]. The newly synthesized ruthenium(II) complex was highly active in the reaction of alkenes to alkanes (Scheme 20, equation A), and in the formation of $E$-alkenes from alkynes (Scheme 20, equation B). Mono- and di-substituted alkenes reduced easily without double bond isomerization; however, sterically hindered tri- and tetra-substituted derivatives showed no reaction under the same reaction conditions [90]. Diphenylacetylene was selectively converted to diphenylethylene, while alkynes with less bulky substituents showed a mixture of $E$ and $Z$ alkenes, and further converted to the corresponding alkanes (over-hydrogenation). The proposed mechanism for the TH of olefins is the classic dihydride route $[1,90]$.

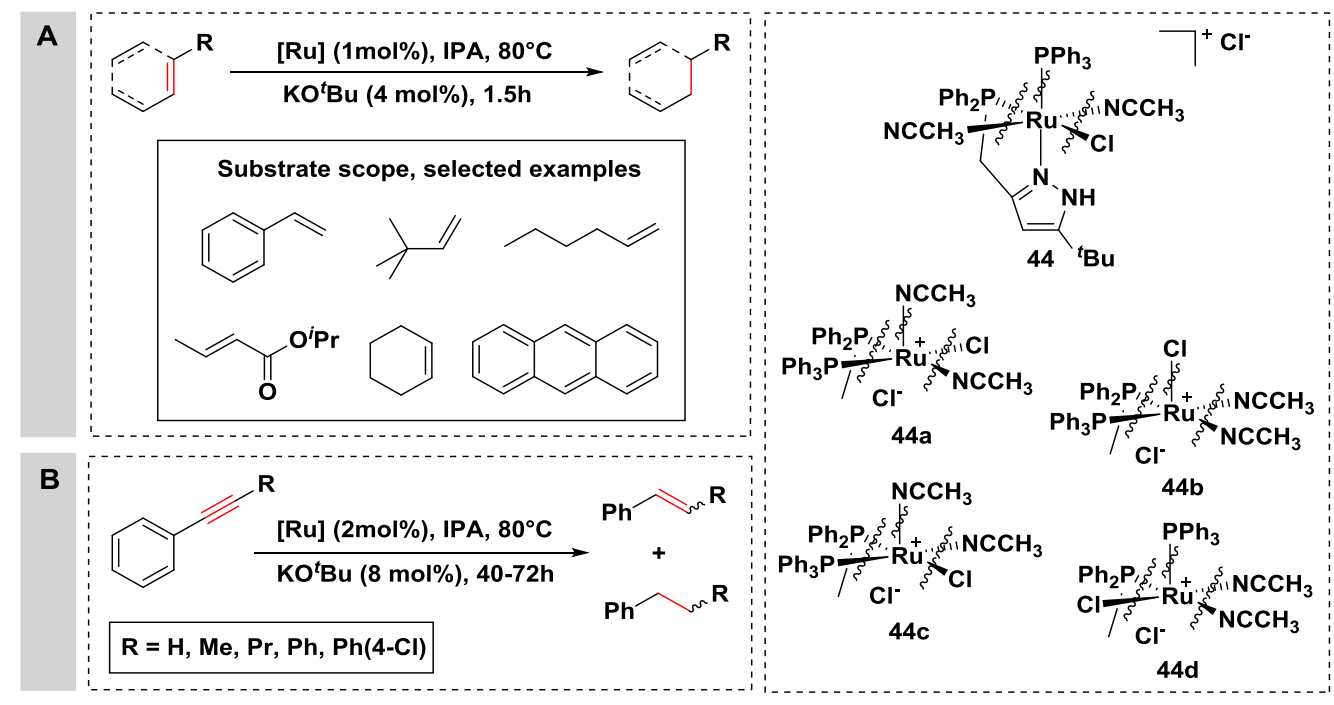

Scheme 20. Transfer hydrogenation with ruthenium(II) pyrazole-phosphine-type complexes.

\subsubsection{Hydrogen Transfer with Palladium}

Chemoselective transfer hydrogenation was observed in the presence of pincer-Pd complexes [91]. A wide range of the alcohols were tested as possible hydrogen donor molecules, such as $\mathrm{MeOH}$, $\mathrm{EtOH},{ }^{n} \mathrm{PrOH},{ }^{i} \mathrm{PrOH},{ }^{n} \mathrm{BuOH}$, and ${ }^{i} \mathrm{BuOH}$. Under the optimized reaction conditions, the most suitable hydrogen donor was ${ }^{n} \mathrm{BuOH}$, at reflux conditions, good to excellent yields were determined (81-98\%) (Scheme 21) [91]. Deuterium-labeling experiments revealed that the reaction mechanism most probably occurs via the formation of a pincer-Pd-hydride intermediate.

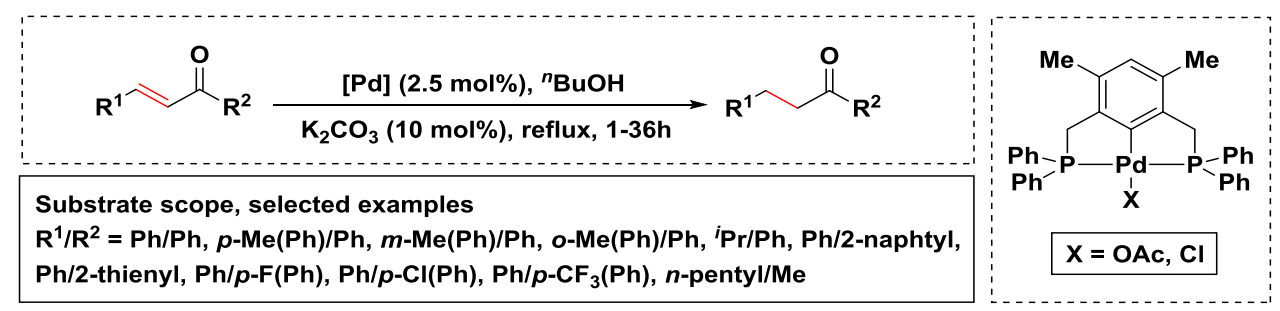

Scheme 21. Transfer hydrogenation of $\alpha, \beta$-unsaturated ketones with pincer-Pd complexes.

Catalytic asymmetric conjugate reduction of $\beta, \beta$-disubstituted $\alpha, \beta$-unsaturated carbonyl compounds in the presence of chiral Pd complexes (45-47, Scheme 22) was reported [92]. In the presence of ethanol as the hydrogen source, high chemical yields (85-99\%) and high enantioselectivity (74-99\%), depending from the actual substrate, was observed (Scheme 22, equation A, catalyst (R)-47). The approach was also applied successfully in the asymmetric synthesis of warfarin (a well-known anticoagulant) (Scheme 22, equation B, catalyst (S)-47). In order to gain an insight into the possible 
reaction mechanism, the reaction was carried out in $d$-ethanol. The results showed that the cationic $\mathrm{Pd}$ hydride generated from the corresponding $\operatorname{Pd}(\mu-\mathrm{OH})$ complex and ethanol can act as a chiral reducing agent, driving the reaction to the saturated carbonyl species (Scheme 22) [92].

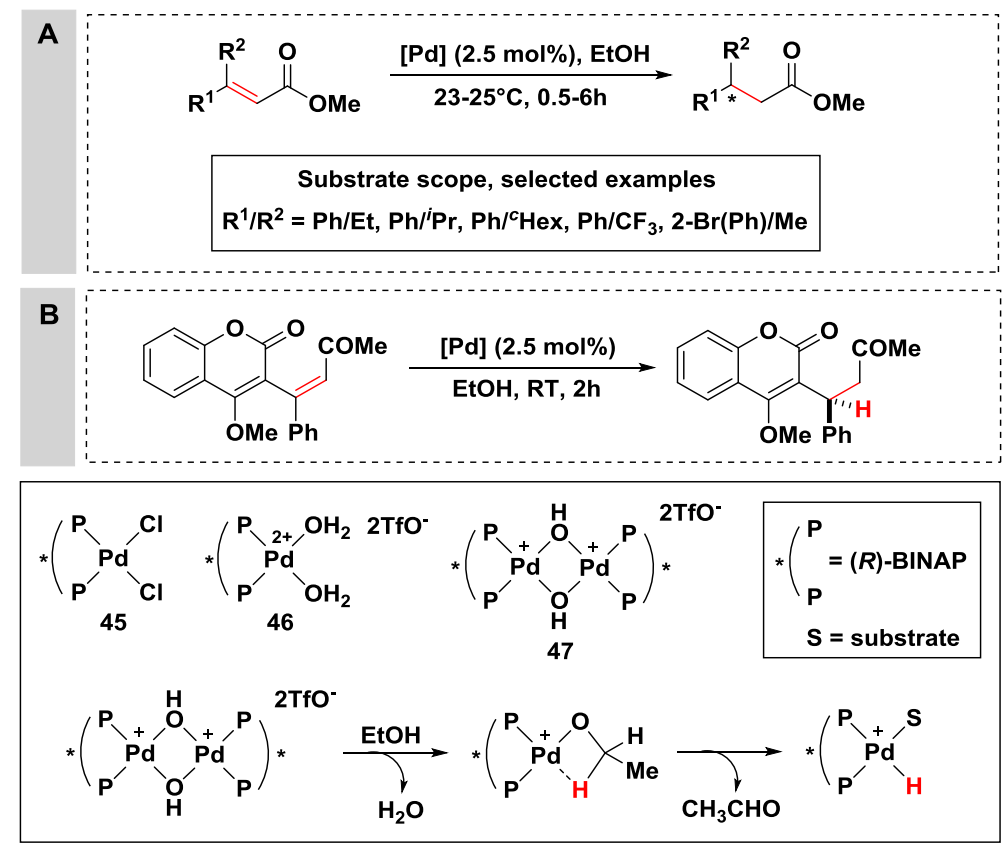

Scheme 22. Palladium-catalyzed asymmetric conjugate reduction of enones. (RT = room temperature).

Porphyrin-based complexes with inner and outer metals in their structure were investigated in the hydrogen transfer reaction of chalcone with 1-butanol as the hydrogen source and reaction media (the catalytic allylation of benzaldehyde was studied in parallel) (Scheme 23) [93]. A porphyrin complex having palladium as the outer metal showed good catalytic activity, however it was observed that the 1,4-reduction capability could be further increased with the variation of the inner metal (such as $\mathrm{Zn}, \mathrm{Ni})$. Several homogeneous counterparts such as $\mathrm{Pd}(\mathrm{OAc})_{2}$, $\left[\mathrm{PdCl}_{2}\left(\mathrm{PPh}_{3}\right)_{2}\right]$ and $\left[\mathrm{Pd}_{2}(\mathrm{dba})_{3}\right]$ $(\mathrm{dba}=$ dibenzalacetone) were tested, but showed no conversion, indicating that the catalytic activity is linked to the pincer complexes, and not to palladium colloids [93].

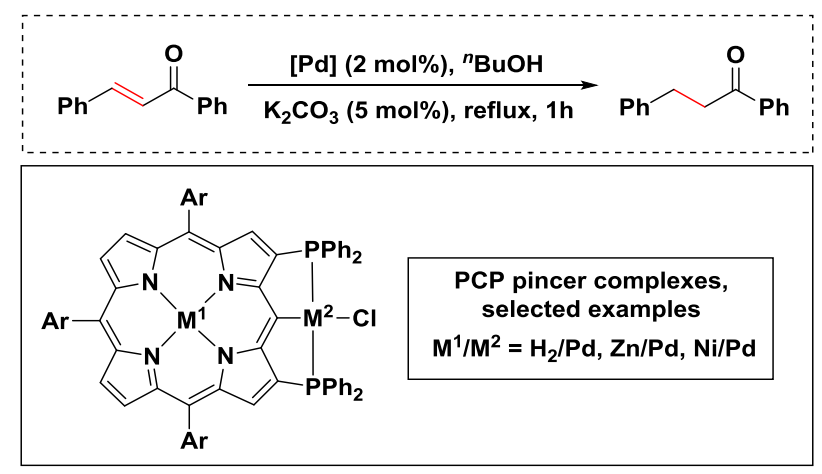

Scheme 23. Porphyrin-based palladium catalysts for the transfer hydrogenation of chalcone.

The dominance of the noble metal-catalyzed hydrogen transfer reactions towards homogeneous catalysis can be seen clearly; nevertheless, interesting achievements based on heterogeneous catalysis (supported metals or immobilized homogeneous representatives) were presented as well in the literature $[29,94]$. 
Glycerol as a hydrogen source and solvent was used efficiently in the reduction of alkenes, and mono- and diarylated alkenes in the presence of palladium supported on activated carbon $(5 \mathrm{wt} \%)$ (Scheme 24) [95]. A lower reactivity was observed for the diarylated substrates, due to steric effects, compared to monoarylated counterparts. A similar trend was observed for 1-hexene and 1-octene, due to their lower solubilities in glycerol [95].

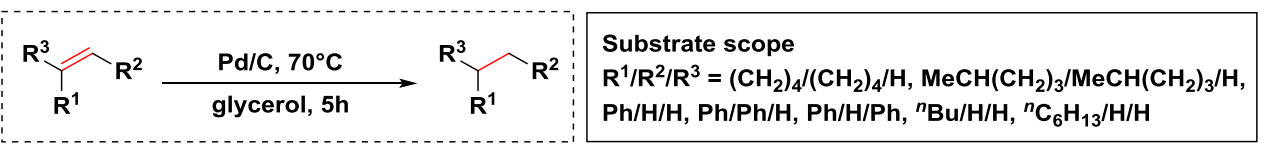

Scheme 24. Transfer hydrogenation with glycerol as a hydrogen donor in the presence of $\mathrm{Pd} / \mathrm{C}$.

Palladium supported on activated carbon (Pd/10 mol \%) in a combination with triethylamine $\left(\mathrm{NEt}_{3}\right)$ was used in conjugate reduction experiments of activated double bond-containing representatives (e.g., tert-butyl acrylate, benzylidene tert-butyl ketone, benzylidene-acetone, cinnamonitrile) (Scheme 25) [96,97].

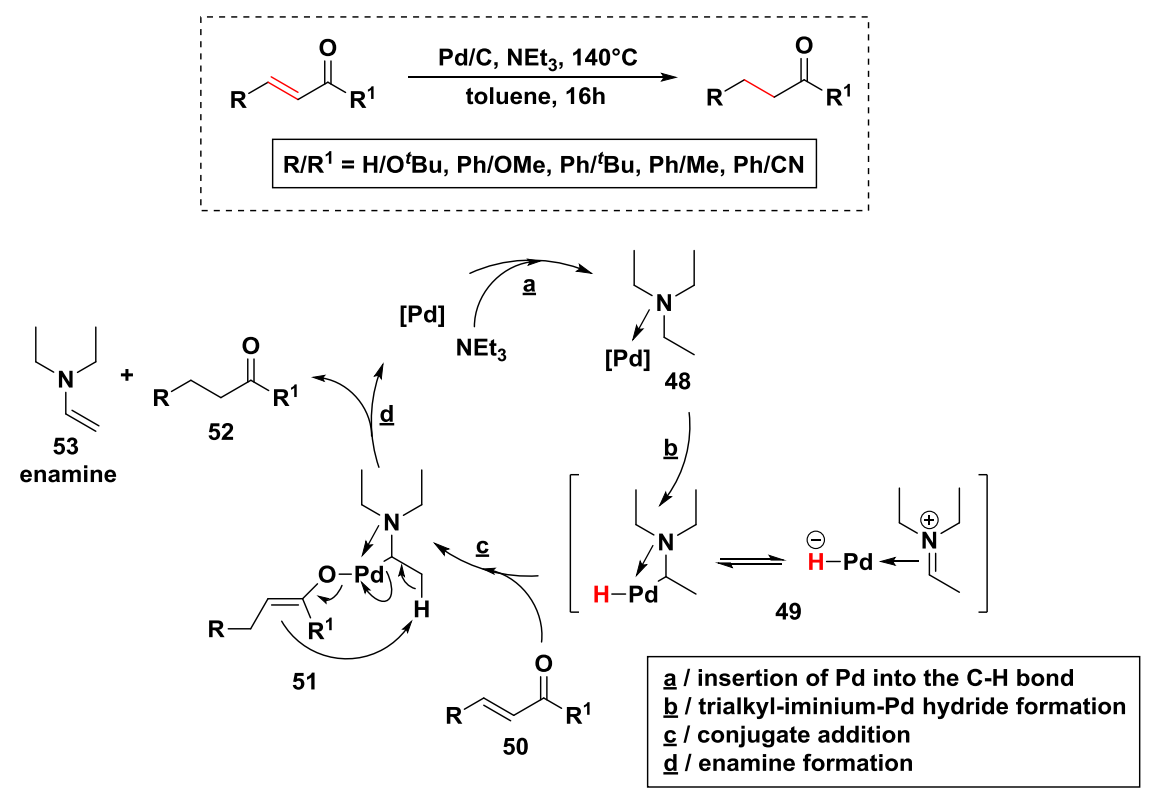

Scheme 25. Palladium-catalyzed reduction of alkenes in the presence of triethylamine as a hydrogen source.

The tertiary amine served as the H-donor molecule. From a mechanistic viewpoint, it was supposed that, after the insertion of $\mathrm{Pd}$ into the $\mathrm{C}-\mathrm{H}$ bond $\alpha$ to the nitrogen atom (48), a trialkyliminium-palladium hydride complex forms (49), followed by the conjugate reduction and enamine (53) formation step. Interestingly, when ethanol was used as the solvent and hydride source, under the same reaction conditions, no reaction was observed. The scope of the investigations was extended to isomerization reactions as well $[96,97]$.

$\mathrm{H}$-Transfer reactions of internal alkenes with tertiary amines on carbon-supported noble metals such as palladium, platinum, and rhodium was studied in the condensed phase [98]. The highest overall catalytic activity was observed for Pd/C (Pd/10 mol \%) in the presence of $\mathrm{N}, \mathrm{N}$-diisopropylethylamine, 1-ethylpyrrolidine, and 1-ethylpiperidine, while methyl oleate and trans-5-decene were used as starting materials (Scheme 26) [98]. 


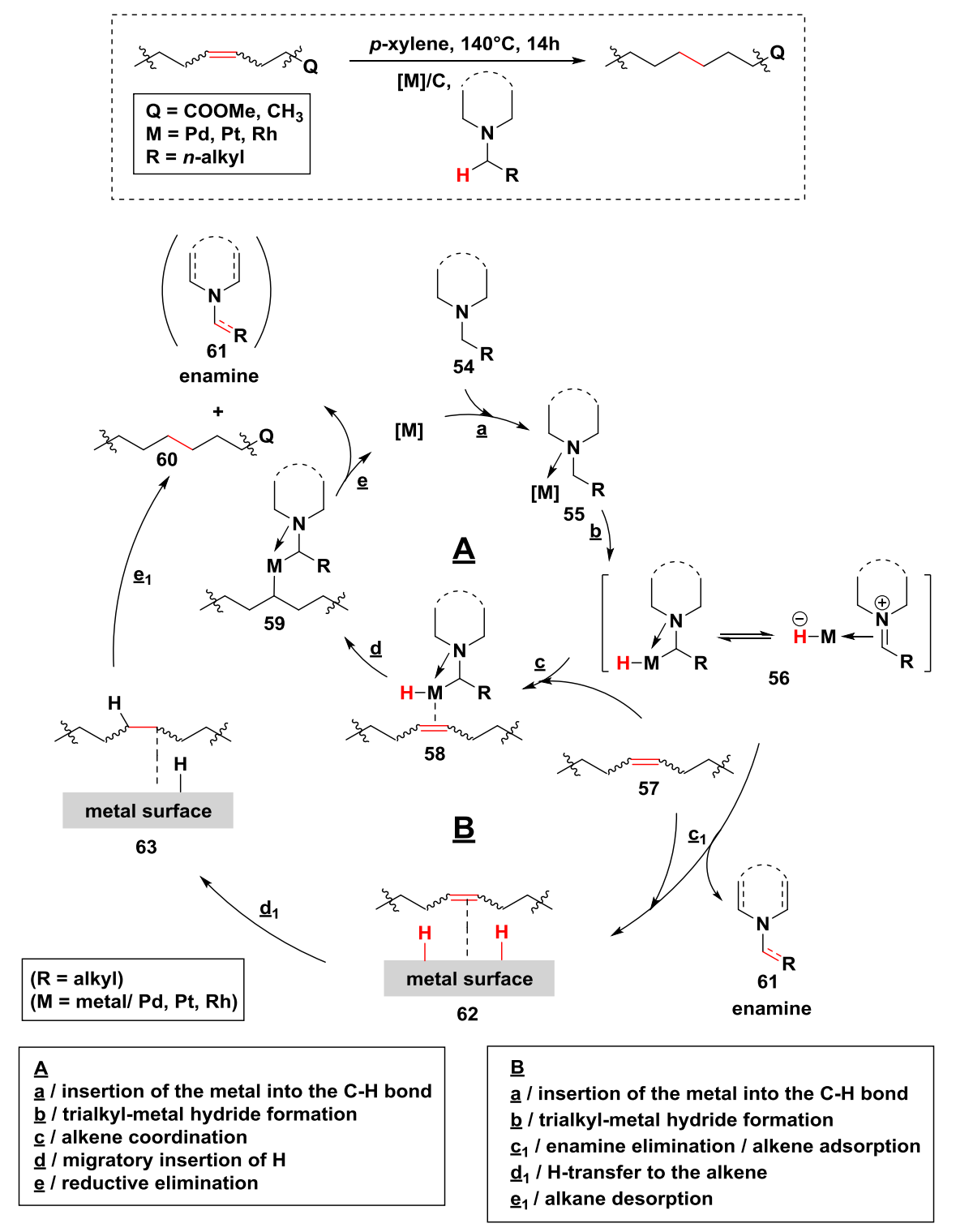

Scheme 26. Noble metal-catalyzed hydrogen transfer in the presence of tertiary amines as hydrogen sources: Hydrogen transfer via surface complex formation (route A); Reduction with dissociative adsorption (route $\mathbf{B})$.

Triethylamine and amines with longer alkyl chain (n-butyl, $n$-pentyl, $n$-hexyl) showed minor hydrogen donation abilities. The formation of 1-ethyl-pyrrole (from 1-ethylpyrrolidine) and pyridine (from 1-ethylpiperidine) was observed, which clearly indicated that the source of the newly incorporated two hydrogen atoms was the amine [98]. Two modes of activation of the alkene were described: one possibility if the alkene competitively adsorbs on the metal with the alkyl amine (Scheme 26, route A), leading to the formation of a metal-alkene surface complex (58); the second is the dissociative adsorption of the trialkyl amine on the metal surface (Scheme 26, route B), initiating a direct alkene adsorption (62). It was concluded however, that route $\mathbf{B}$ (the sequential way) is entropically more favored then A (concerted way), and none of the pathways could be excluded.

\section{Concluding Remarks}

The operational simplicity, the possibility of mild reaction conditions, and high catalytic activity and selectivity make the hydrogen transfer reactions an elegant way of add hydrogen in a system. These positive reduction processes operating with hydrogen transfer in the absence of molecular 
hydrogen, deserve a prominent position in the ranks of chemical transformations. The further increase of the application possibilities, not only in synthetic chemistry, but also for the production of fine chemicals, can be predicted.

As was discussed for transition metals $\mathrm{Rh}, \mathrm{Ru}$, and $\mathrm{Pd}$ the dominant route to transfer hydrogen is the hydridic pathway. The hydridic route can be divided into two further subgroups: to the monohydride and dihydride mechanisms. As an illustration, rhodium (and iridium as well) follows the monohydridic route, while the hydrogen transfer in the case of ruthenium is largely determined by the actual catalyst used. The monohydridic route consists of two subgroups described as the outer-sphere (without substrate coordination) pathway (stepwise or concerted routes) and the inner-sphere (with substrate coordination) mechanisms. Nevertheless, the nature of a mechanism is determined by the chemical nature (electronic and steric properties) of the starting material and the ligand, as well.

Hydrogen transfer is clearly a privileged property of homogeneous catalysts. One of the major challenges for the future will be how to translate homogeneous understanding to heterogeneous counterparts. In the case of a supported metal-based heterogeneous catalyst, one can manipulate the surface properties, and with these modifications, manipulate the adsorption/desorption capabilities of substrates on the surface, or influence the nature of a catalytically active site (particle size tuning, guest metal used). A heterogeneous system with all of its advantages (e.g., easy separation, recyclability, relatively long lifetime) and with the possibility of asymmetric hydrogen transfer, without coverage of the surface with a chiral component, would represent a remarkable step forward in this field.

Acknowledgments: E. B. thank G. L. Haller for fruitful and extensive discussions.

Conflicts of Interest: The author declares no conflict of interest.

\section{References}

1. Klomp, D.; Hanefeld, U.; Peters, J.A. Transfer hydrogenation including the Meerwein-Ponndorf-Verley reduction. In The Handbook of Homogeneous Hydrogenation, 1st ed.; de Vries, J.G., Elsevier, C.J., Eds.; WILEY-VCH Verlag GmbH \& Co. KGaA: Weinheim, Germany, 2007; Chapter 20, pp. 585-630, ISBN 978-3-527-31161-3.

2. Hydrogen transfer in organic and organometallic reactions. In Hydrogen-Transfer Reactions, 1st ed.; Hynes, J.T., Klinman, J.P., Limbach, H.-H., Schowen, R.L., Eds.; WILEY-VCH Verlag GmbH \& Co. KGaA: Weinheim, Germany, 2007; Part V, Chapter 18-21, pp. 563-634, ISBN 978-3-527-30777-7.

3. Meerwein, H.; Schmidt, R. Ein neues Verfahren zur Reduktion von Aldehyden und Ketonen. Justus Liebigs Ann. Chem. 1925, 444, 221-238. [CrossRef]

4. Verley, A. The exchange of functional groups between two molecules. The passage of ketones to alcohols and the reverse. Bull. Soc. Chim. Fr. 1925, 37, 871-874.

5. Ponndorf, W. Der reversible Austausch der Oxydationsstufen zwischen Aldehyden oder Ketonen einerseits und primären oder sekundären Alkoholen anderseits. Angew. Chem. 1926, 29, 138-143. [CrossRef]

6. Lund, H. Aluminium-isopropylat als Reduktionsmittel. Eine allgemeine Methode zur Carbonylreduktion. Ber. Dtsch. Chem. Ges. 1937, 70, 1520-1525. [CrossRef]

7. Oppenauer, R.V. Eine Methode der Dehydrierung von Sekundären Alkoholen zu Ketonen. I. Zur Herstellung von Sterinketonen und Sexualhormonen. Recl. Trav. Chim. Pays-Bas 1937, 56, 137-144. [CrossRef]

8. Namy, J.L.; Souppe, J.; Collin, J.; Kagan, H.B. New preparations of lanthanide alkoxides and their catalytical activity in Meerwein-Ponndorf-Verley-Oppenauer reactions. J. Org. Chem. 1984, 49, 2045-2049. [CrossRef]

9. Okano, T.; Matsuoka, M.; Konishi, H.; Kiji, J. Meerwein-Ponndorf-Verley reduction of ketones and aldehydes catalyzed by lanthanide tri-2-propoxides. Chem. Lett. 1987, 181-184. [CrossRef]

10. Campell, E.J.; Zhou, H.; Nguyen, S.T. Catalytic Meerwein-Pondorf-Verley reduction by simple aluminum complexes. Org. Lett. 2001, 3, 2391-2393. [CrossRef]

11. Ooi, T.; Miura, T.; Itagaki, Y.; Ichikawa, H.; Maruoka, K. Catalytic Meerwein-Ponndorf-Verley (MPV) and Oppenauer (OPP) reactions: Remarkable acceleration of the hydride transfer by powerful bidentate aluminum alkoxides. Synthesis 2002, 279-291. [CrossRef] 
12. Liu, Y.-C.; Ko, B.-T.; Huang, B.-H.; Lin, C.-C. Reduction of aldehydes and ketones catalyzed by a novel aluminum alkoxide: Mechanistic studies of Meerwein-Ponndorf-Verley reaction. Organometallics 2002, 21, 2066-2069. [CrossRef]

13. de Graauw, C.F.; Peters, J.A.; van Bekkum, H.; Huskens, J. Meerwein-Ponndorf-Verley reductions and Oppenauer oxidations: An integrated approach. Synthesis 1994, 1994, 1007-1017. [CrossRef]

14. Nishide, K.; Node, M. Recent development of asymmetric syntheses based on the Meerwein-Ponndorf-Verley reduction. Chirality 2002, 14, 759-767. [CrossRef]

15. Haddad, Y.M.Y.; Henbest, H.B.; Husbands, J.; Mitchell, T.R.B. Reduction of cyclohexanones to axial alcohols via iridium-containing catalysts. Proc. Chem. Soc. 1964, 361. [CrossRef]

16. Osborn, J.A.; Jardine, F.H.; Young, J.F.; Wilkinson, G. The preparation and properties of tris(triphenylphosphine)halogenorhodium(I) and some reactions thereof including catalytic homogeneous hydrogenation of olefins and acetylenes and their derivatives. J. Chem. Soc. A 1966, 1711-1732. [CrossRef]

17. Gladiali, S.; Pinna, L.; Delogu, G.; De Martin, S.; Zassinovich, G.; Mestroni, G. Optically active phenanthrolines in asymmetric catalysis. III. Highly efficient enantioselective transfer hydrogenation of acetophenone by chiral rhodium/3-alkyl phenanthroline catalysts. Tetrahedron 1990, 1, 635-648. [CrossRef]

18. Uson, R.; Oro, L.A.; Sariego, R.; Esteruelas, M.A. Catalytic transfer hydrogenation by cationic rhodium(I) complexes. J. Organomet. Chem. 1981, 214, 399-404. [CrossRef]

19. Kvintovics, P.; James, B.R.; Heil, B. Enantioselective transfer hydrogenation of ketones using a rhodium catalyst containing a methionine sulphoxide ligand. Chem. Commun. 1986, 1810-1811. [CrossRef]

20. Fujii, A.; Hashiguchi, S.; Uematsu, N.; Ikariya, T.; Noyori, R. Ruthenium(II)-catalyzed asymmetric transfer hydrogenation of ketones using a formic acid-triethylamine mixture. J. Am. Chem. Soc. 1996, 118, 2521-2522. [CrossRef]

21. Blacker, A.J. Enantioselective transfer hydrogenation. In The Handbook of Homogeneous Hydrogenation, 1st ed.; de Vries, J.G., Elsevier, C.J., Eds.; WILEY-VCH Verlag GmbH \& Co. KGaA: Weinheim, Germany, 2007; Chapter 35, pp. 1215-1244, ISBN 978-3-527-31161-3.

22. Watanabe, Y.; Ohta, T.; Tsuji, Y. Ruthenium-catalyzed reduction of carbonyl compounds using formic acid. Bull. Chem. Soc. Jpn. 1982, 55, 2441-2444. [CrossRef]

23. Khai, B.; Arcelli, A. Selective reduction of aldehydes by a formic acid- trialkylamine- $\mathrm{RuCl}_{2}\left(\mathrm{PPh}_{3}\right)_{3}$ system . Tetrahedron Lett. 1985, 26, 3365-3368. [CrossRef]

24. Brunner, H.; Leitner, W. Enantioselective catalytic transfer-hydrogenation of $\alpha, \beta$-unsaturated carboxylic acids with triethylammonium formate. Angew. Chem. Int. Ed. 1988, 27, 1180-1181. [CrossRef]

25. Lange, S.; Leitner, W. Mechanistic aspects of hydrogen addition during enantioselective rhodium-catalysed reduction of $\mathrm{C}=\mathrm{C}$ double bonds with formic acid/triethylamine or molecular hydrogen. J. Chem. Soc. Dalton Trans. 2002, 752-758. [CrossRef]

26. Wu, X.; Li, X.; King, F.; Xiao, J. Insight into and practical application of pH-controlled asymmetric transfer hydrogenation of aromatic ketones in water. Angew. Chem. Int. Ed. 2005, 44, 3407-3411. [CrossRef] [PubMed]

27. Dinh, P.M.; Howarth, J.A.; Hudnott, A.R.; Williams, J.M.J.; Harris, W. Catalytic racemisation of alcohols: Applications to enzymatic resolution reactions. Tetrahedron Lett. 1996, 37, 7623-7626. [CrossRef]

28. Gladiali, S.; Alberico, E. Asymmetric transfer hydrogenation: Chiral ligands and applications. Chem. Soc. Rev. 2006, 35, 226-236. [CrossRef] [PubMed]

29. Wang, D.; Astruc, D. The golden age of transfer hydrogenation. Chem. Rev. 2015, 115, 6621-6686. [CrossRef] [PubMed]

30. Models for biological hydrogen transfer. In Hydrogen-Transfer Reactions, 1st ed.; Hynes, J.T., Klinman, J.P., Limbach, H.-H., Schowen, R.L., Eds.; WILEY-VCH Verlag GmbH \& Co. KGaA: Weinheim, Germany, 2007; Parts I-II, Chapter 1-8, pp. 947-1200, ISBN 978-3-527-30777-7.

31. Baird, M.C.; Nyman, C.J.; Wilkinson, G. The decarbonylation of aldehydes by tris(triphenylphosphine)chlororhodium(I). J. Chem. Soc. A 1968, 348-351. [CrossRef]

32. Ohno, K.; Tsuji, J. Organic synthesis by means of noble metal compounds. XXXV. Novel decarbonylation reactions of aldehydes and acyl halides using rhodium complexes. J. Am. Chem. Soc. 1968, 90, 99-107. [CrossRef] 
33. Imai, H.; Nishiguchi, T.; Fukuzumi, K. Transfer hydrogenation and transfer hydrogenolysis. 11. Facile dehydrogenation of aromatic hydrocarbons and the mechanism of the hydrogen transfer from indan, tetralin, and dioxane to aldehydes catalyzed by dihydridotetrakis(triphenylphosphine)ruthenium(II). J. Org. Chem. 1976, 41, 2688-2693. [CrossRef]

34. Nishiguchi, T.; Fukuzumi, K. Transfer-hydrogenation and transfer-hydrogenolysis. III. Hydrogen transfer from dioxane to olefins catalyzed by chlorotris(triphenylphosphine)rhodium(I). J. Am. Chem. Soc. 1974, 96, 1893-1897. [CrossRef]

35. Nishiguchi, T.; Tachi, K.; Fukuzumi, K. Hydrogen transfer from dioxane to an olefin catalyzed by chlorotris(triphenylphosphine)rhodium(I). J. Am. Chem. Soc. 1972, 94, 8916-8917. [CrossRef]

36. Imai, H.; Nishiguchi, T.; Fukuzumi, K. Transfer hydrogenation and transfer hydrogenolysis. IX. Hydrogen transfer from organic compounds to aldehydes and ketones catalyzed by dihydridotetrakis(triphenylphosphine)ruthenium(II). J. Org. Chem. 1976, 41, 665-671. [CrossRef]

37. Imai, H.; Nishiguchi, T.; Fukuzumi, K. Transfer hydrogenation and transfer hydrogenolysis. 13. Hydrogen transfer from cyclic amines to aromatic nitro compounds catalyzed by noble metal salts. J. Org. Chem. 1977, 42, 431-434. [CrossRef]

38. Imai, H.; Nishiguchi, T.; Tanaka, M.; Fukuzumi, K. Transfer hydrogenation and transfer hydrogenolysis. 14. Cleavage of carbon-halogen bond by the hydrogen transfer from organic compounds catalyzed by noble metal salts. J. Org. Chem. 1977, 42, 2309-2313. [CrossRef]

39. Pàmies, O.; Bäckvall, J.-E. Studies on the mechanism of metal-catalyzed hydrogen transfer from alcohols to ketones. Chem. Eur. J. 2001, 7, 5052-5058. [CrossRef]

40. Hashiguchi, S.; Fujii, A.; Takehara, J.; Ikariya, T.; Noyori, R. Asymmetric transfer hydrogenation of aromatic ketones catalyzed by chiral ruthenium(II) complexes. J. Am. Chem. Soc. 1995, 117, 7562-7653. [CrossRef]

41. Noyori, R.; Hashiguchi, S. Asymmetric transfer hydrogenation catalyzed by chiral ruthenium complexes. Acc. Chem. Res. 1997, 30, 97-102. [CrossRef]

42. Murata, K.; Ikariya, T.; Noyori, R. New chiral rhodium and iridium complexes with chiral diamine ligands for asymmetric transfer hydrogenation of aromatic ketones. J. Org. Chem. 1999, 64, 2186-2187. [CrossRef]

43. Albrecht, M.; Crabtree, R.H.; Mata, J.; Peris, E. Chelating bis-carbene rhodium(III) complexes in transfer hydrogenation of ketones and imines. Chem. Commun. 2002, 32-33. [CrossRef]

44. Gierz, V.; Urbanaite, A.; Seyboldt, A.; Kunz, D. Rhodium complexes bearing 1,10-phenantroline analouge bis-NHC ligands are active catalysts for transfer hydrogenation of ketones. Organometallics 2012, 31, 7532-7538. [CrossRef]

45. Sluijter, S.N.; Elsevier, C.J. Synthesis and reactivity of heteroditopic dicarbene rhodium(I) and iridium(I) complexes bearing chelating 1,2,3-triazolylidene-imidazolylidene ligands. Organometallics 2014, 33, 6389-6397. [CrossRef]

46. Ramasamy, B.; Gangwar, M.K.; Ghosh, P. Chiral oxazolidine-fused N-heterocyclic carbene complexes of rhodium and iridium and their utility in the asymmetric transfer hydrogenation of ketones. Eur. J. Inorg. Chem. 2017, 3253-3268. [CrossRef]

47. Aboo, A.A.; Bennett, E.L.; Deeprose, M.; Robertson, C.M.; Iggo, J.A.; Xiao, J. Methanol as hydrogen source: Transfer hydrogenation of aromatic aldehydes with rhodacycle. Chem. Commun. 2018, 54, 11805-11808. [CrossRef] [PubMed]

48. Farrell, K.; Müller-Bunz, H.; Albrecht, M. Synthesis, isomerization, and catalytic transfer hydrogenation activity of rhodium(III) complexes containing both chelating dicarbenes and diphosphine ligands. Organometallics 2015, 34, 5723-5733. [CrossRef]

49. Aranyos, A.; Csjernyik, G.; Szabó, K.J.; Bäckvall, J.-E. Evidence for a ruthenium dihydride species as the active catalyst in the $\mathrm{RuCl}_{2}\left(\mathrm{PPh}_{3}\right)$ - catalyzed hydrogen transfer reaction in the presence of base. Chem. Commun. 1999, 351-352. [CrossRef]

50. Chowdhury, R.L.; Bäckvall, J.-E. Efficient ruthenium-catalysed transfer hydrogenation of ketones by propan-2-ol. Chem. Commun. 1991, 1063-1064. [CrossRef]

51. Haack, K.-J.; Hashiguchi, S.; Fujii, A.; Ikariya, T.; Noyori, R. The catalyst precursor, catalyst, and intermediate in the $\mathrm{Ru}^{\mathrm{II}}$-promoted asymmetric hydrogen transfer between alcohols and ketones. Angew. Chem. Int. Ed. 1997, 36, 285-288. [CrossRef] 
52. Yamakawa, M.; Ito, H.; Noyori, R. The metal-ligand bifunctional catalysis: A theoretical study on the ruthenium(II)-catalyzed hydrogen transfer between alcohols and carbonyl compounds. J. Am. Chem. Soc. 2000, 122, 1466-1478. [CrossRef]

53. Handgraaf, J.-W.; Reek, J.N.H.; Meijer, E.J. Iridium(I) versus ruthenium(II). A computational study of the transition metal-catalyzed transfer hydrogenation of ketones. Organometallics 2003, 22, 3150-3157. [CrossRef]

54. Hayes, A.; Clarckson, G.; Wills, M. The importance of 1,2-anti-disubstitution in monotosylated diamine ligands for ruthenium(II)-catalysed asymmetric transfer hydrogenation. Tetrahedron 2004, 15, 2079-2084. [CrossRef]

55. Sortais, J.-B.; Ritleng, V.; Voelklin, A.; Holuigue, A.; Smail, H.; Balroy, L.; Sirlin, C.; Verzijl, G.K.M.; Boogers, J.A.F.; de Vries, A.H.M.; et al. Cycloruthenated primary and secondary amines as efficient catalyst precursors for asymmetric transfer hydrogenation. Org. Lett. 2005, 7, 1247-1250. [CrossRef] [PubMed]

56. Baratta, W.; Da Ros, P.; Del Zotto, A.; Sechi, A.; Zangrando, E.; Rigo, P. Cyclometalated ruthenium(II) complexes as highly active transfer hydrogenation catalysts. Angew. Chem. Int. Ed. 2004, 43, 3584-3588. [CrossRef] [PubMed]

57. Baratta, W.; Chelucci, G.; Gladiali, S.; Siega, K.; Toniutti, M.; Zanette, M.; Zangrando, E.; Rigo, P. Ruthenium(II) terdentate CNN complexes: Superlative catalysts for the hydrogen-transfer reduction of ketones by reversible insertion of a carbonyl group into the $\mathrm{Ru}-\mathrm{H}$ bond. Angew. Chem. Int. Ed. 2005, 44, 6214-6219. [CrossRef] [PubMed]

58. Nishibayashi, Y.; Takei, I.; Uemura, S.; Hidai, M. Extremely high enantioselective redox reaction of ketones and alcohols catalyzed by $\mathrm{RuCl}_{2}\left(\mathrm{PPh}_{3}\right)$ (oxazolinylferrocenylphosphine). Organometallics 1999, 18, 2291-2293. [CrossRef]

59. Alonso, D.; Nordin, S.; Roth, P.; Tarnai, T.; Anderson, P. 2-Azanorbornyl alcohols: Very efficient ligands for ruthenium-catalyzed asymmetric transfer hydrogenation of aromatic ketones. J. Org. Chem. 2000, 65, 3116-3122. [CrossRef] [PubMed]

60. Nordin, S.; Roth, P.; Tarnai, T.; Alonso, D.; Brandt, P.; Anderson, P. Remote dipole effects as a means to accelerate [Ru(amino alcohol)]-catalyzed transfer hydrogenation of ketones. Chem. Eur. J. 2001, 7, 1431-1436. [CrossRef]

61. Alonso, D.A.; Brandt, P.; Nordin, S.J.M.; Andersson, P.G. Ru(arene)(amino alcohol)-catalyzed transfer hydrogenation of ketones: Mechanism and origin of enantioselectivity. J. Am. Chem. Soc. 1999, 121, 9580-9588. [CrossRef]

62. Arikawa, Y.; Ueoka, M.; Matoba, K.; Nishibashi, Y.; Hidai, M.; Uemura, S. Ruthenium(II)-catalyzed asymmetric transfer hydrogenation of ketones using chiral oxazolinylferrocenylphosphines and one of their Ru(II) complex. J. Organomet. Chem. 1999, 572, 163-168. [CrossRef]

63. Gladiali, S.; Alberico, E. Transferhydrogenations. In Transition Metals for Organic Synthesis-Building Blocks and Fine Chemicals, 2nd ed.; Beller, M., Bolm, C., Eds.; WILEY-VCH Verlag GmbH \& Co. KGaA: Weinheim, Germany, 2004; Chapter 1.3, pp. 145-162, ISBN 3-527-30613-7.

64. Matsumura, K.; Hashiguchi, S.; Ikariya, T.; Noyori, R. Asymmetric transfer hydrogenation of $\alpha, \beta$-acetylenic ketones. J. Am. Chem. Soc. 1997, 119, 8738-8739. [CrossRef]

65. Palmer, M.J.; Wills, M. Asymmetric transfer hydrogenation of $\mathrm{C}=\mathrm{O}$ and $\mathrm{C}=\mathrm{N}$ bonds. Tetrahedron 1999, 10, 2045-2061. [CrossRef]

66. Shvo, Y.; Czarkie, D.; Rahamim, Y.; Chodosh, D.F. A new group of ruthenium complexes: Structure and catalysis. J. Am. Chem. Soc. 1986, 108, 7400-7402. [CrossRef]

67. Samec, J.S.M.; Bäckvall, J.-E. Ruthenium-catalyzed transfer hydrogenation of imines by propan-2-ol in benzene. Chem. Eur. J. 2002, 8, 2955-2961. [CrossRef]

68. Comas-Vives, A.; Ujaque, G.; Lledós, A. Hydrogen transfer to ketones catalyzed by Shvo's ruthenium hydride complex: A mechanistic insight. Organometallics 2007, 26, 4135-4144. [CrossRef]

69. Karvembu, R.; Prabhakaran, R.; Natarajan, K. Shvo's diruthenium complex: A robust catalyst. Coord. Chem. Rev. 2005, 249, 911-918. [CrossRef]

70. Jung, H.M.; Shin, S.T.; Kim, Y.H.; Kim, M.-J.; Park, J. X-ray structure and reactivity of $\left(\eta^{4}\right.$-tetraphenylcyclopentadienone $)(\mathrm{CO})_{2} \mathrm{Ru}\left(\mathrm{HOCHMe}_{2}\right)$ : Unexpected stability of the neutral 2-propanolruthenium(0) complex with respect to $\beta$-hydride elimination. Organometallics 2001, 20, 3370-3372. [CrossRef] 
71. Casey, C.P.; Singer, S.W.; Powell, D.R.; Hayashi, R.K.; Kavana, M. Hydrogen transfer to carbonyls and imines from a hydroxycyclopentadienyl ruthenium hydride: Evidence for concerted hydride and proton transfer. J. Am. Chem. Soc. 2001, 123, 1090-1100. [CrossRef] [PubMed]

72. Johnson, J.B.; Bäckvall, J.-E. Mechanism of ruthenium-catalyzed hydrogen transfer reactions. Concerted transfer of $\mathrm{OH}$ and $\mathrm{CH}$ hydrogens from an alcohol to a (cyclopentadienone)ruthenium complex. J. Org. Chem. 2003, 68, 7681-7684. [CrossRef] [PubMed]

73. Lundberg, H.; Adolfsson, H. Ruthenium-catalyzed asymmetric transfer hydrogenation of ketones in ethanol. Tetrahedron Lett. 2011, 52, 2754-2758. [CrossRef]

74. Giboulot, S.; Baldino, S.; Ballico, M.; Nedden, H.G.; Zuccaccia, D.; Baratta, W. Cyclometalated dicarbonyl ruthenium catalysts for transfer hydrogenation and hydrogenation of carbonyl compounds. Organometallics 2018, 37, 2136-2146. [CrossRef]

75. Chelucci, G.; Baldino, S.; Baratta, W. Ruthenium and osmium complexes containing 2-(aminomethyl)pyridine (ampy)-based ligands in catalysis. Coord. Chem. Rev. 2015, 300, 29-85. [CrossRef]

76. Matsumura, K.; Arai, N.; Hori, K.; Saito, T.; Sayo, N.; Ohkuma, T. Chiral ruthenabicyclic complexes: Precatalysts for rapid, enantioselective, and wide-Scope hydrogenation of ketones. J. Am. Chem. Soc. 2011, 133, 10696-10699. [CrossRef] [PubMed]

77. Dub, P.A.; Gordon, J.C. The mechanism of enantioselective ketone reduction with Noyori and Noyori-Ikariya bifunctional catalysts. Dalton Trans. 2016, 45, 6756-6781. [CrossRef]

78. Dub, P.A.; Henson, N.J.; Martin, R.L.; Gordon, J.C. Unraveling the mechanism of the asymmetric hydrogenation of acetophenone by $\left[\mathrm{RuX}_{2}\right.$ (diphosphine)(1,2-diamine)] catalysts. J. Am. Chem. Soc. 2014, 136, 3505-3521. [CrossRef]

79. Maity, A.; Sil, A.; Patra, S.K. Ruthenium(II) complexes of $4^{\prime}$-(aryl)-2,2':6',2"'-terpyridyl ligands as simple catalysts for the transfer hydrogenation of ketones. Eur. J. Inorg. Chem. 2018, 2018, 4063-4073. [CrossRef]

80. Du, W.; Wu, P.; Wang, Q.; Yu, Z. Ruthenium(II) complex catalysts bearing a pyridyl-based benzimidazolylbenzotriazolyl ligand for transfer hydrogenation of ketones. Organometallics 2013, 32, 3083-3090. [CrossRef]

81. Du, W.; Wang, Q.; Wang, L.; Yu, Z. Ruthenium complex catalysts cupported by a bis(trifluoromethyl)pyrazolylpyridyl-based NNN ligand for transfer hydrogenation of ketones. Organometallics 2014, 33, 974-982. [CrossRef]

82. Zhao, M.; Yu, Z.; Yan, S.; Li, Y. Room-temperature Ru(II)-catalyzed transfer hydrogenation of ketones and aldehydes in air. Tetrahedron Lett. 2009, 50, 4624-4628. [CrossRef]

83. Zhu, Z.; Zhang, J.; Fu, H.; Yuan, M.; Zheng, X.; Chen, H.; Li, R. Construction of pincer-type symmetrical ruthenium(II) complexes bearing pyridyl-2,6-pyrazolyl arms: Catalytic behavior in transfer hydrogenation of ketones. RSC Adv. 2014, 4, 52734-52739. [CrossRef]

84. Li, K.; Niu, J.-L.; Yang, M.-Z.; Li, Z.; Wu, L.-Y.; Hao, X.-Q.; Song, M.-P. New type of 2,6-bis(imidazo[1,2-a]pyridin2-yl)pyridine-based ruthenium complexes: Active catalysts for transfer hydrogenation of ketones. Organometallics 2015, 34, 1170-1176. [CrossRef]

85. Menéndez-Pedregal, E.; Vaquero, M.; Lastra, E.; Gamasa, P.; Pizzano, A. Highly enantioselective hydrogenation of $\mathrm{N}$-aryl imines derived from acetophenones by using $\mathrm{Ru}$-pybox complexes under hydrogenation or transfer hydrogenation conditions in isopropanol. Chem. Eur. J. 2015, 21, 549-553. [CrossRef]

86. Moore, C.M.; Szymczak, N.K. 6,6'-Dihydroxy terpyridine: A proton-responsive bifunctional ligand and its application in catalytic transfer hydrogenation of ketones. Chem. Commun. 2013, 49, 400-402. [CrossRef] [PubMed]

87. Paul, B.; Chakrabarti, K.; Kundu, S. Optimum bifunctionality in a 2-(2-pyridyl-2-ol)-1,10-phenanthroline based ruthenium complex for transfer hydrogenation of ketones and nitriles: Impact of the number of 2-hydroxypyridine fragments. Dalton Trans. 2016, 45, 11162-11171. [CrossRef] [PubMed]

88. Melle, P.; Manoharan, Y.; Albrecht, M. Modular pincer-type pyridylidene amide ruthenium(II) complexes for efficient transfer hydrogenation catalysis. Inorg. Chem. 2018, 57, 11761-11774. [CrossRef]

89. Farrar-Tobar, R.A.; Tin, S.; de Vries, J.G. Selective transfer hydrogenation of $\alpha, \beta$-unsaturated carbonyl compounds. Top. Organomet. Chem. 2018. [CrossRef]

90. Alshakova, I.D.; Gabidullin, B.; Nikonov, G.I. Ru-Catalyzed transfer hydrogenation of nitriles, aromatics, olefins, alkynes and esters. ChemCatChem 2018, 10, 4860-4869. [CrossRef] 
91. Ding, B.; Zhang, Z.; Liu, Y.; Sugiya, M.; Imamoto, T.; Zhang, W. Chemoselective transfer hydrogenation of $\alpha, \beta$-unsaturated ketones catalyzed by pincer-Pd complexes using alcohol as a hydrogen source. Org. Lett. 2013, 15, 3690-3693. [CrossRef]

92. Tsuchiya, Y.; Hamashima, Y.; Sodeoka, M. A new entry to Pd-H chemistry: Catalytic asymmetric conjugate reduction of enones with EtOH and a highly ennatioselective synthesis of warfarin. Org. Lett. 2006, 8, 4851-4854. [CrossRef]

93. Fujimoto, K.; Yoneda, T.; Yorimitsu, H.; Osuka, A. Synthesis and catalytic activities of porphyrin-based PCP pincer complexes. Angew. Chem. Int. Ed. 2014, 53, 1127-1130. [CrossRef]

94. Muzart, J. Pd-Catalyzed hydrogen-transfer reactions from alcohols to $\mathrm{C}=\mathrm{C}, \mathrm{C}=\mathrm{O}$, and $\mathrm{C}=\mathrm{N}$ bonds. Eur. J. Org. Chem. 2015, 2015, 5693-5707. [CrossRef]

95. Wolfson, A.; Dlugy, C.; Shotland, Y.; Tavor, D. Glycerol as solvent and hydrogen donor in transfer hydrogenation-dehydrogenation reactions. Tetrahedron Lett. 2009, 50, 5951-5953. [CrossRef]

96. Coquerel, Y.; Rodriguez, J. Catalytic properties of the Pd/C-Trimethylamine system. Arkivoc 2008, 11, 227-237.

97. Coquerel, Y.; Brémond, P.; Rodriguez, J. Pd-H From Pd/C and triethylamine: Implications in palladium catalyzed reactions involving amines. J. Organomet. Chem. 2007, 692, 4805-4808. [CrossRef]

98. Yang, G.; Bauer, T.J.; Haller, G.L.; Baráth, E. H-Transfer reactions of internal alkenes with tertiary amines as H-donors on carbon supported noble metals. Org. Biomol. Chem. 2018, 16, 1172-1177. [CrossRef] [PubMed]

(c) 2018 by the author. Licensee MDPI, Basel, Switzerland. This article is an open access article distributed under the terms and conditions of the Creative Commons Attribution (CC BY) license (http://creativecommons.org/licenses/by/4.0/). 